\title{
Role of the GInK signal transduction protein in the regulation of nitrogen assimilation in Escherichia coli
}

\author{
Mariette R. Atkinson and Alexander J. Ninfa* \\ Department of Biological Chemistry, University of \\ Michigan Medical School, Ann Arbor, MI 48109-0606, \\ USA.
}

\section{Summary}

Two structurally similar but functionally distinct PIIlike proteins, PII and GInK, regulate nitrogen assimilation in Escherichia coli. Studies with cells indicated that both PII (the $g I n B$ product) and GInK (the $g / n K$ product) acted through the kinase/phosphatase NRII [NtrB, the $g / n L$ (ntrB) product] to reduce transcription initiation from Ntr promoters, apparently by regulating the phosphorylation state of the transcriptional activator NRI $\sim \mathrm{P}$ (NtrC $\sim \mathrm{P}$, the phosphorylated form of the gInG (ntrC) product). Both GInK and PII also acted through adenylyltransferase (ATase, the gInE product) to regulate the adenylylation state of glutamine synthetase (GS). The activity of both GInK and PII was regulated by the signal-transducing uridylyltransferase/ uridylyl-removing enzyme (UTase/UR, gInD product). Our experiments indicate that either PII or GInK could effectively regulate ATase, but that PII was required for the efficient regulation of NRII required to prevent expression of $g \operatorname{In} A$, which encodes GS. Yet, GInK also participated in regulation of NRII. Although cells that lack either PII or GInK grew well, cells lacking both of these proteins were defective for growth on nitrogen-rich minimal media. This defect was alleviated by the loss of NRII, and was apparently due to unregulated expression of the Ntr regulon. Also, mutations in $g / n K$, designated $g / n K^{*}$, were obtained as suppressors of the $\mathrm{Ntr}^{-}$phenotype of a double mutant lacking PII and the UTase/UR. These suppressors appeared to reduce, but not eliminate, the ability of GInK to prevent Ntr gene expression by acting through NRII. We hypothesize that one role of GInK is to regulate the expression of the level of NRI $\sim P$ during conditions of severe nitrogen starvation, and by so doing to contribute to the regulation of certain Ntr genes.

Received 17 February, 1998; revised 14 April, 1998; accepted 17 April, 1998. *For correspondence. E-mail aninfa@umich.edu; Tel. 313763 8065; Fax 3137634581.
Introduction

Nitrogen regulation of gene transcription has been intensively studied in Escherichia coli and related bacteria, and a resulting working model for this regulation and the regulation of glutamine synthetase adenylylation is shown in Fig. 1 (reviewed in Rhee et al., 1985a; 1989; Kamberov et al., 1994; Merrick and Edwards, 1995; Ninfa et al., 1995; Magasanik, 1996; Reitzer, 1996a,b). The key sensory components are the uridylyltransferase/uridylyl-removing enzyme (UTase/UR, gInD product), which is controlled allosterically by glutamine (Jiang et al., 1998), and the PII signal transduction protein ( $g \ln B$ product), which is reversibly uridylylated in response to the absence or presence of this signal. PII and PII-UMP, which are allosterically regulated by 2-ketoglutarate, interact with adenylyltransferase (ATase, glnE product) to regulate adenylylation (inactivation) and deadenylylation (activation) of glutamine synthetase (GS, gInA gene product; Fig. 1, right). In addition, PII interacts with NRII [gInL (ntrB) product] to bring about the dephosphorylation of the transcription factor $\mathrm{NRI} \sim \mathrm{P}[\mathrm{NRI}$ is product of $g \ln G(\mathrm{ntr} C)]$. This prevents transcription of $g \ln A$ and other genes in response to nitrogen limitation (Ninfa and Magasanik, 1986; Fig. 1, left). PIIUMP does not interact with NRII (Atkinson et al., 1994; Kamberov et al., 1995; E. S. Kamberov and A. J. Ninfa, unpublished).

There are two known routes by which NRI becomes phosphorylated (Fig. 1, left). NRII binds ATP and phosphorylates itself on a histidine, and these phosphoryl groups are transferred to NRI; phosphoryl groups are also directly transferred from acetyl phosphate to NRI (Feng et al., 1992). Either of these routes provides sufficient phosphorylation of NRI to permit full expression of $g \ln A$, but both routes of NRI phosphorylation are required for growth under certain nitrogen starvation conditions (Feng et al., 1992). NRII and NRI constitute a bacterial two-component system, with numerous homologues found in prokaryotes and eukaryotes (for reviews see Parkinson and Kofoid, 1992; Kamberov et al., 1994; Hoch and Silhavy, 1995; Ninfa et al., 1995; Ninfa, 1996). In enteric bacteria, many such two-component systems are functioning simultaneously to regulate different cellular processes, and for several of these systems regulation by acetyl phosphate has been observed (Deretic et al., 1992; Lukat et al., 1992; Wanner et al., 1992; McCleary and Stock, 1994; Pruss and Wolfe, 1994; McCleary, 1996; reviewed in 


\section{Transcriptional Activation}

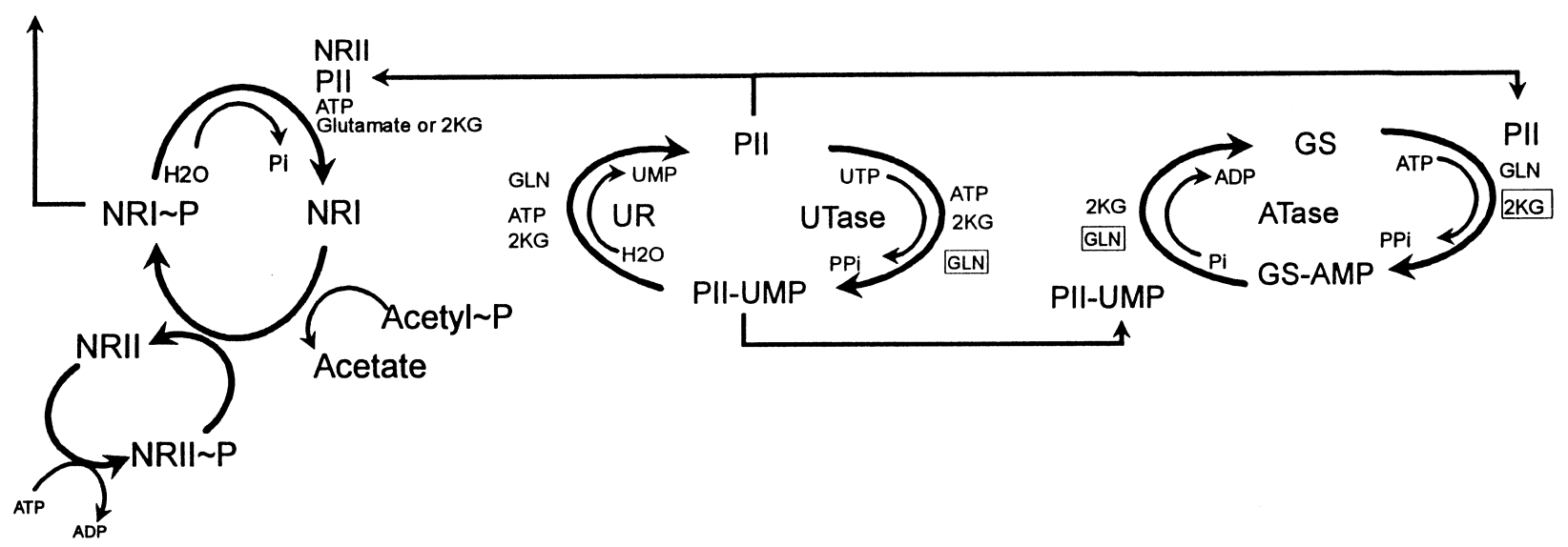

Fig. 1. Signal transduction system regulating GS adenylylation and the expression of the Ntr regulon. Proteins depicted are: NRI, nitrogen regulator I ( $g \ln G(n t r C)$ product); NRII, nitrogen regulator II ( $g \operatorname{lnL}(n t r B)$ product); PII, glnB product; UTase/UR, uridylyltransferase/uridylylremoving enzyme (activities depicted separately) ( $g \ln D$ product); ATase, adenylyltransferase ( $g / n E$ product); GS, glutamine synthetase ( $g / n A$ product). Small molecule effectors: GLN, glutamine; 2KG, 2-ketoglutarate. Boxed effectors are inhibitors of the indicated reaction, and unboxed effectors are activators of the indicated reaction. The figure is similar to Fig. 1 of Jiang et al. (1997).

McCleary et al., 1993). Indeed, NRII seems to be an important regulator of the intracellular acetyl phosphate concentration (Pruss and Wolfe, 1994), presumably because the PII-activated dephosphorylation of NRI $\sim$ P by NRII acts as a sink for the phosphoryl groups. There is no known regulation of the phosphorylation of NRI by NRII. Thus, the expression of $g \ln A$ and the Ntr regulon, as well as the intracellular concentration of acetyl phosphate, appear to be regulated by the PII-dependent dephosphorylation of $\mathrm{NRI} \sim \mathrm{P}$ by NRII.

Previous studies have suggested that transcription of $g \ln A$ is activated by a very low intracellular concentration of $\mathrm{NRI} \sim \mathrm{P}$, whereas transcription of certain other nitrogenregulated genes, such as those permitting use of arginine or histidine as a nitrogen source, requires a higher intracellular concentration of NRI P (Pahel et al., 1982; Reitzer and Magasanik, 1986). Indeed, the expression of $g \ln A$ is diminished in vivo and in vitro at very high concentrations of NRI P (Shiau et al., 1992; Feng et al., 1995). The $\mathrm{NRI} \sim \mathrm{P}$ concentration dependence for transcriptional activation of various Ntr promoters may be due to the quantity, quality and location of enhancer and silencer sequences bound by $\mathrm{NRI} \sim \mathrm{P}$, the extent of occupancy of the promoter sequences by polymerase and by other factors such as the stability of the open transcription complexes formed at the various promoters (Feng et al., 1995). In essence, each Ntr promoter is designed to be activated only when the concentration of $\mathrm{NRI} \sim \mathrm{P}$ is within a certain range.

Very serious defects of the model shown in Fig. 1 have been known for over a decade (Bueno et al., 1985). The model predicts that, as the UTase/UR acts through PII, in strains lacking PII the $g / n D$ genotype should be irrelevant. However, this is not found.
The $g \ln D$-encoded UTase/UR is required for the use of arginine as a nitrogen source $\left(\mathrm{Ntr}^{+}\right.$phenotype), as predicted by the model. Cells lacking only PII are able to use arginine as a nitrogen source and have elevated levels of $g \ln A$ expression under all conditions, as predicted by the model (Bueno et al., 1985, Fig. 1). However, a $g \ln B \operatorname{gln} D$ double mutant (strain $\mathrm{BD}$ ), lacking both PII and UTase/ $\mathrm{UR}$, has elevated expression of $g \ln A$ but is $\mathrm{Ntr}^{-}$. The $\mathrm{Ntr}^{-}$phenotype of the doubly mutant BD strain suggested that this strain had a high enough intracellular concentration of NRI $\sim P$ to activate $g / n A$, but could not generate a high enough concentration of $\mathrm{NRI} \sim \mathrm{P}$ to activate the genes required for the use of arginine as a nitrogen source. This $\mathrm{Ntr}^{-}$phenotype was due to a direct requirement for the $\mathrm{g} / \mathrm{n} D$ product, UTase/UR, as transformation of strain BD with a plasmid containing only $g \ln D^{+}$and vector sequences restored the $\mathrm{Ntr}^{+}$phenotype (unpublished observations). Thus, the UTase/UR clearly had a role in the regulation of Ntr gene expression in the absence of PII.

Another defect in the model, noted earlier (van Heeswijk et al., 1995; 1996), is that cells lacking only PII have normal regulation of the GS adenylylation state in response to nitrogen availability. This finding is also discordant with results with purified components, which indicated that the deadenylylation of GS-AMP by the ATase absolutely required PII-UMP in vitro (Stadtman et al., 1970). In the doubly mutant $g \ln B g \ln D$ strain (strain BD), GS is overadenylylated under nitrogen-limiting conditions. Thus, the UTase/UR was required for regulation of GS adenylylation even in the absence of PII (reviewed in Ninfa et al., 1995).

The data discussed above suggested the existence of at least one additional gene product that is capable of regulating Ntr gene expression and GS adenylylation state,

(C) 1998 Blackwell Science Ltd, Molecular Microbiology, 29, 431-447 
and also suggested that the activity of the unidentified gene product(s) was regulated by the UTase/UR (reviewed in Ninfa et al., 1995). Recent studies have revealed that $E$. coli contains a gene, designated glnK, that encodes a homologue of the PII protein (Allikmets et al., 1993; van Heeswijk et al., 1995; 1996). The glnK product was observed to be uridylylated in cell extracts by the UTase/UR (van Heeswijk et al., 1996). These experiments suggested that the glnK gene product may be part of the nitrogen regulatory system and may account for the requirement for the UTase/UR in the strain deleted for $g \ln B$. Purified GlnK was observed to activate the adenylylation of GS by ATase in vitro (van Heeswijk et al., 1996). Unlike the PII protein, which is essentially present constitutively, immunoblotting experiments indicated that the expression of glnK was itself nitrogen regulated (van Heeswijk et al., 1993; 1996). Furthermore, sequences corresponding to an Ntr promoter were identified upstream from glnK (van Heeswijk et al., 1996). Thus, it could be anticipated that GInK and PII are likely to have functionally distinct roles.

van Heeswijk et al. (1996) proposed a model in which the role of GInK was to slow down the transcriptional response when nitrogen-starved cells encounter ammonia. They hypothesized that the redundancy of GInK and PII results in a slow (GInK) and fast (PII) signal transduction system. They proposed that in nitrogen-starved cells, NRI, NRII and GInK are at high concentration, and a rapid response to an increase in ammonia could be inefficient if this increase is transitory. They hypothesized that the internal concentrations of NRI, NRII and GInK are only lowered after prolonged exposure to ammonia, and that NRI, NRII and GInK serve as 'memory proteins' that buffer the signal transduction system against transitory changes in nitrogen availability.

In the absence of a glnK mutant, the role of this gene in nitrogen regulation remained speculative. As a further complication, the prior immunoblotting studies suggested that the glnK product was not detectable in a strain isogenic with strain BD (van Heeswijk et al., 1996). Thus, it was unclear whether glnK or yet another gene was responsible for the $\mathrm{Ntr}^{-}$phenotype of the strain $\mathrm{BD}$.

We took three approaches to determine whether glnK was involved in nitrogen regulation, and more specifically, if $g / n K^{+}$was responsible for the $\mathrm{Ntr}^{-}$phenotype of the $g \ln B g \ln D$ double mutant (strain BD). First, we used the known sequence of $g / n K$ to construct a null mutation in glnK in vitro, and recombined this mutation onto the $E$. coli chromosome. The effect of this null mutation was then assessed in isolation, and in combination with mutations in other regulatory genes. Second, we constructed a lac $Z$ transcriptional fusion to the glnK promoter, placed this fusion at another location on the chromosome and examined its regulation in various genetic backgrounds. The results of these two studies indicated that glnK acted through $g I n L$ to regulate certain Ntr promoters, including the glnK promoter, but did not have an important role in the regulation of the $g \ln A$ promoter. During the course of these studies, we also observed that glutamine synthetase activity appears to regulate, directly or indirectly, the level of acetyl phosphate. Finally, we isolated spontaneous mutations that permitted the BD strain to use arginine as a nitrogen source, and characterized these mutations. Among the spontaneous mutants, we identified 10 mutations that mapped in glnK. Most of these were located in a part of gInK predicted to encode the T loop, based on the PII structure (Carr et al., 1996). The T loop of PIl is known to be the part that interacts with the PII receptors, and receptor specificity mutations altering PII map to this part of the protein (Jiang et al., 1997). Thus, the suppressor analysis directly indicated that GlnK is responsible for the $\mathrm{Ntr}^{-}$phenotype of strain BD, and that GInK has a role in negative regulation of the Ntr regulon.

\section{Results}

Physiological characterization of the role of $\mathrm{glnK}$ in
nitrogen regulation

To assess the role of $g \ln K$ in regulation of $g \ln A$, the GS activity and the adenylylation state were measured in adapted cultures using the $\gamma$-glutamyl transferase assay (reviewed in Rhee et al., 1985b). To assess the expression of the Ntr regulon, two tests were used. First, the ability of cells to grow on arginine as the sole nitrogen source was tested. Cells must be able to generate a high intracellular concentration of $\mathrm{NRI} \sim \mathrm{P}$ to use this nitrogen source (reviewed in Reitzer et al., 1996b). Second, the expression of the nitrogen-regulated glnK promoter was assessed by measuring $\beta$-galactosidase activity in cells containing a glnK::lacZ fusion that was present in single copy in the trp locus (Experimental procedures).

The regulation of GS in the 'wild-type' strain YMC10 containing the glnK::lacZ fusion (YMC10 $\phi$ ) was the same as previously observed in YMC10 lacking the fusion (Tables 1 and 2, Atkinson and Ninfa, 1992). That is, the level of the enzyme was elevated about sevenfold by nitrogen starvation, with the level of unadenylylated GS subunits elevated about 32-fold (Table 1). In contrast, the expression of the glnK::lacZ fusion was regulated about 2400 -fold under the same conditions (Table 1). This great degree of regulation was largely due to the near absence of fusion expression under nitrogen-rich conditions (Table 1). The wild-type strain grew well on arginine as the sole nitrogen source.

In strain $\mathrm{B} \phi$, deleted for $g \ln B$ (and thus lacking PII) and containing the $g \operatorname{lnK}:: / a c Z$ fusion, the level of total GS was high regardless of nitrogen availability, as noted previously for strain B (Bueno et al., 1985, Tables 2 and 3). However, as already noted, the regulation of GS adenylylation state 
Table 1. Glutamine synthetase and $\beta$-galactosidase expression in adapted cultures and Ntr phenotype.

\begin{tabular}{|c|c|c|c|c|c|}
\hline \multirow[b]{2}{*}{ Strain } & \multicolumn{2}{|c|}{ Glutamine synthetase ${ }^{a}\left(n^{b}\right)$} & \multicolumn{2}{|c|}{$\beta$-Galactosidase } & \multirow[b]{2}{*}{$\mathrm{Ntr}^{\mathrm{c}}$} \\
\hline & Ggln ${ }^{d}$ & GNgln & Ggln & GNgln & \\
\hline YMC10ф & $1198(2.8)$ & $173(10.0)$ & 4866 & 2 & +++ \\
\hline $\mathrm{B} \phi$ & 1535 (3.7) & 1565 (11.4) & 3111 & 556 & +++ \\
\hline $\mathrm{L} \phi$ & $569(6.4)$ & $508(11.2)$ & 444 & 200 & $+++^{\mathrm{e}}$ \\
\hline $\mathrm{D \phi}$ & $293(9.3)$ & $92(9.4)$ & $<2$ & $<2$ & - \\
\hline $\mathrm{K} \phi$ & 957 (3.3) & $234(10.4)$ & 1978 & 44 & +++ \\
\hline $\mathrm{P \phi}$ & $886(2.4)$ & 129 (10.4) & 5444 & $<2$ & $+1-^{e}$ \\
\hline $\mathrm{BD} \phi$ & 1557 (10.7) & $1530(11.5)$ & 431 & 391 & - \\
\hline $\mathrm{BL} \phi$ & $720(8.0)$ & 607 (11.3) & 233 & 153 & $+++^{\mathrm{e}}$ \\
\hline $\mathrm{KL} \phi$ & $618(2.4)$ & $622(11.3)$ & 524 & 164 & $+++^{\mathrm{e}}$ \\
\hline LE $\phi$ & $884(1.3)$ & $125(4.0)$ & 1851 & 44 & $+++^{e}$ \\
\hline LP $\phi$ & 38 (ND) & 41 (ND) & 4 & $<2$ & - \\
\hline LEP $\phi$ & 40 (ND) & 22 (ND) & $<2$ & $<2$ & - \\
\hline BKL $\phi$ & 2281 (11.5) & 906 (11.6) & 1471 & 222 & $+++^{e}$ \\
\hline BLEK & $966(2.1)$ & $178(4.3)$ & ND & ND & $++^{\mathrm{e}}$ \\
\hline BLEKP & 80 (ND) & 25 (ND) & ND & ND & - \\
\hline BDM $\phi$ & $1600(11.1)$ & $1852(11.7)$ & 467 & 540 & - \\
\hline ВDМ $\phi g \ln K 8$ & 2235 (11.4) & 1998 (11.5) & 3956 & 2267 & +++ \\
\hline ВDM $\phi g \ln K 9$ & 2610 (11.5) & 2000 (11.6) & 3356 & 1207 & +++ \\
\hline
\end{tabular}

a. GS transferase activity. Values are the average of two to six cultures. Results from duplicate cultures generally differed by $<15 \%$. Cultures were grown overnight in the indicated medium, diluted to $\mathrm{OD}_{600}=0.02$ and grown at $30^{\circ} \mathrm{C}$ to $\mathrm{OD}=0.5$.

b. Adenylylation state, determined by performing the transferase assay in the presence of $\mathrm{Mn}^{2+}$ (total activity) and $\mathrm{Mg}^{2+}$ (deadenylylated activity only), expressed as average number of adenylylated subunits/GS dodecamer.

c. Growth on solid glucose-arginine medium supplemented with tryptophan $(0.04 \% \mathrm{w} / \mathrm{v})$. Growth was assessed after $60 \mathrm{~h}$ at $37^{\circ} \mathrm{C}$. +++ signifies vigorous, wild-type growth; ++ signifies less vigorous growth; $+/$ - signifies pinpoint colonies; and - signifies the inability to grow. d. Media used were Ggln, glucose-glutamine; GNgln, glucose-ammonia-glutamine. In all cases, glucose was present at $0.4 \%(\mathrm{w} / \mathrm{v})$ and the nitrogen sources were each present at $0.2 \%(\mathrm{w} / \mathrm{v})$.

e. Strains lacking $g I n L$ or the ability to form acetyl phosphate are unable to grow on liquid glucose-arginine medium, a more demanding test of Ntr gene expression (Feng et al., 1992). ND, not determined. occurred in this strain despite the absence of PII. In the experiments shown, the level of unadenylylated GS subunits was regulated about 14-fold in response to nitrogen availability (Table 1). Similar results were obtained for strain $B$, lacking the glnK::lacZ fusion (Tables 2 and 3). In strain $\mathrm{B} \phi$, the $g \ln K:: / a c Z$ fusion was regulated about sixfold by nitrogen availability, with the induced level slightly less than that seen in the wild-type background and the uninduced level $\approx 275$-fold higher than in the wild type. As noted for strain $B$, strain $B \phi$ grew like the wild type on arginine as the sole nitrogen source.

In strain D $\phi$, containing the glnD99::Tn 10 mutation and
Table 2. Effect of $g l n K^{*}$ alleles on the expression of $g \ln A$ and adenylylation state of GS.

\begin{tabular}{|c|c|c|c|}
\hline \multirow[b]{2}{*}{ Strain } & \multirow[b]{2}{*}{ Relevant genotype } & \multicolumn{2}{|c|}{ Glutamine synthetase ${ }^{a}\left(n^{b}\right)$} \\
\hline & & $\mathrm{Ggln}^{\mathrm{c}}$ & GNgln \\
\hline YMC10 & Wild type & $1076(2.3)$ & $167(9.3)$ \\
\hline B & $\Delta g \ln B$ & $1253(2.9)$ & $1126(11.4)$ \\
\hline $\mathrm{K}$ & $\Delta m d l-g \ln K:: k a n$ & $1590(3.0)$ & $177(10.2)$ \\
\hline BK-8 & $\Delta g \ln B \quad m d l:: c h l . . g \operatorname{lnK} 8(\mathrm{R} 47 \rightarrow \mathrm{W})$ & $1250(3.0)$ & $1243(11.1)$ \\
\hline BK-9 & $\Delta g \ln B$ mdl ::chl..glnK9 $(\mathrm{R} 47 \rightarrow \mathrm{L})$ & $1390(4.4)$ & $1280(11.2)$ \\
\hline
\end{tabular}

a. GS transferase activity. Values are from single cultures for strains YMC10, B and K, and from three cultures for BK- 8 and BK-9. Results from triplicate cultures differed by $<15 \%$. Cultures were grown overnight in the indicated medium, diluted to $\mathrm{OD}_{600}=0.02$ and grown at $30^{\circ} \mathrm{C}$ to $\mathrm{OD}=0.5$.

b. Adenylylation state, determined by performing the transferase assay in the presence of $\mathrm{Mn}^{2+}$ (total activity) and $\mathrm{Mg}^{2+}$ (deadenylylated activity only), expressed as average number of adenylylated subunits/GS dodecamer.

c. Media used were Ggln, glucose-glutamine; GNgln, glucose-ammonia-glutamine In all cases, glucose was present at $0.4 \%(\mathrm{w} / \mathrm{v})$ and the nitrogen sources were each present at $0.2 \%(w / v)$. 
Table 3. Complementation of strains BK and B with plasmids expressing PII or GlnK.

\begin{tabular}{|c|c|c|c|}
\hline \multirow[b]{2}{*}{ Strain } & \multirow[b]{2}{*}{ Relevant genotype } & \multicolumn{2}{|c|}{ Glutamine synthetase ${ }^{a}\left(n^{b}\right)$} \\
\hline & & Ggln ${ }^{c}$ & GNgln \\
\hline B & $\Delta g \ln B$ & $1253(3.3)$ & $909(11.0)$ \\
\hline $\mathrm{K}$ & $\Delta m d l-g l n K:: k a n$ & $1203(2.7)$ & $129(8.5)$ \\
\hline $\mathrm{BK} / \mathrm{pBUC10}$ & $\Delta g \ln B \Delta m d l-g \ln K:: k a n$ pglnB ${ }^{+}$ & $218(3.0)$ & $41(10.4)$ \\
\hline $\mathrm{BK} / \mathrm{pg} \ln \mathrm{K} 2$ & $\Delta g \ln B \Delta m d l-g \ln K:: k a n$ pglnK ${ }^{+}$ & $1014(2.6)$ & $370(10.6)$ \\
\hline B/pBUC10 & $\Delta g \ln B / p g \ln B^{+}$ & $241(3.4)$ & $39(9.5)$ \\
\hline $\mathrm{B} / \mathrm{pg} \ln K 2$ & $\Delta g \ln B / p g \ln K^{+}$ & $945(2.9)$ & $326(10.3)$ \\
\hline
\end{tabular}

a. GS transferase activity. Values are the average of duplicate cultures, which differed by $<15 \%$. Cultures were grown overnight in the indicated medium, diluted to $\mathrm{OD}_{600}=0.02$, and grown at $30^{\circ} \mathrm{C}$ to $\mathrm{OD}=0.5$.

b. Adenylylation state, determined by performing the transferase assay in the presence of $\mathrm{Mn}^{2+}$ (total activity) and $\mathrm{Mg}^{2+}$ (deadenylylated activity only), expressed as average number of adenylylated subunits/GS dodecamer.

c. Media used were Ggln, glucose-glutamine; GNgln, glucose-ammonia-glutamine. Glucose was present at $0.4 \%(\mathrm{w} / \mathrm{v})$ and the nitrogen sources were each present at $0.2 \%(\mathrm{w} / \mathrm{v})$. the $g \ln K:: l a c Z$ fusion, GS expression was induced to a level only $\approx$ one-quarter to one-fifth that found in the wild-type strain when starved, and GS was highly adenylylated regardless of nitrogen availability (Table 1, Bueno et al., 1985). Furthermore, this strain could not use arginine as the sole nitrogen source regardless of whether the medium is solid or liquid, like strain $\mathrm{D}$ (Bueno et al., 1985; Feng et al., 1992). This is as expected, because in the absence of the UTase/UR, PII is unmodified regardless of nitrogen availability. In this strain background the gInK::lacZ fusion was essentially not expressed. Thus, the $g \ln D 99:: \operatorname{Tn} 10$ mutation had a much more severe effect on the regulation of the $g / n K:: / a c Z$ fusion and on the ability of the cells to use arginine as the sole nitrogen source than it did on the expression of $g \ln A$ (Table 1).

Strain BD contains both the deletion of $g \ln B$ and the gInD99::Tn 10 mutation. As noted above, the strain contains high levels of GS regardless of nitrogen availability, but cannot grow on arginine as the sole nitrogen source. Strain $\mathrm{BD} \phi$, which contains in addition the $g / n K:: / a c Z$ fusion, had fully induced levels of GS under both inducing and repressing conditions but, unlike strain $B$, had little ability to regulate the adenylylation state of GS (Table 1). In strain $B D \phi$, the fusion was expressed constitutively at $\approx$ one-tenth the induced wild-type level. Thus, the combination of the $g \ln B$ and $g \ln D$ mutations resulted in constitutive expression of GS, but prevented full expression of gInK::lacZ. Our GS data for this strain are somewhat at variance with previous data (Bueno et al., 1985), in that those workers observed a lower level of GS on both Ggln and GNgln media. Nevertheless, both the data in Table 1 and the previous data (Bueno et al., 1985) show that $g \ln D$ has a role in nitrogen regulation in the absence of $g \ln B$.

In strain $L \phi$, containing a null mutation in $g / n L$ and thus lacking NRII, the level of GS expression was no longer regulated by the availability of nitrogen. The expression of GS in this strain is driven by acetyl phosphate (Feng et al., 1992). The reason why the GS adenylylation state is somewhat elevated in nitrogen-limiting conditions in this strain is not known. In the L $\phi$ strain, the $g / n K:: / a c Z$ fusion was expressed constitutively at about $1 / 10-1 / 20$ the wild-type induced level (Table 1). Previous results from this group (Feng et al., 1992) and another group (Bueno et al., 1985) indicated a higher level of GS expression in strain $L$ (lacking the fusion) on Ggln medium than that reported in Table 1 for strain L $\phi$. Apparently, subtle differences in strain cultivation may affect the accumulation of acetyl phosphate and account for this difference.

Strain BL $\phi$ contains null mutations in $g / n B$ and $g / n L$ and the $g \ln K:: / a c Z$ fusion. The gInL mutation was epistatic to the $g \ln B$ mutation (Table 1), as expected as PII is known to act through NRII to regulate gene transcription (Fig. 1).

\section{Effects of a ginK null mutation}

In strain $\mathrm{K} \phi$, which is isogenic to $\mathrm{YMC} 10 \phi$ except containing the glnK null mutation (Experimental procedures), the expression of GS was similar to the wild type, and GS adenylylation state regulation was normal (Table 1). Similar results were obtained with strain $\mathrm{K}$, which lacks the glnK::lacZ fusion (Tables 2 and 3). Although gInA expression was not greatly altered by the glnK mutation, this mutation did affect the regulation of the $g / n K:: / a c Z$ fusion. The induced level of the fusion expression was less than half that seen in the wild-type background, and the uninduced level was raised 22 -fold, resulting in only 45 -fold regulation by nitrogen availability under the conditions used (Table 1). Strains containing only the glnK mutation grew well on arginine as the sole nitrogen source; indeed, these strains reproducibly displayed an apparent increased rate of growth in liquid glucose-arginine medium. Growth in this nitrogen-limiting medium is a demanding test of $\mathrm{Ntr}$ 
expression; for example, the glnL mutant cannot grow in this medium, nor can strains defective in acetyl phosphate synthesis (Feng et al., 1992). When adapted overnight cultures were diluted into fresh glucose-arginine medium, the wild-type strain and strain lacking PII demonstrated a lag phase that was $2-3 \mathrm{~h}$ longer than strain $\mathrm{K}$, but the maximal growth rate for all three strains was similar (doubling time of $\approx 4.5 \mathrm{~h}$ ), and the final cell yield was similar for all three strains (data not shown). In both the wild type and the glnK mutant, GS was elevated and mainly deadenylylated under these conditions (data not shown). Thus, the gInK mutation had little effect on $g \ln A$ expression but had discernible effects on the expression of other nitrogenregulated genes. Nevertheless, these effects were subtle (Table 1).

We examined whether $g \ln K^{+}$conferred an advantage to the cell in shifting from a condition of nitrogen limitation to a condition of nitrogen excess. For this experiment, the wildtype YMC10 and strain K were adapted to nitrogen-limiting medium and shifted to medium lacking a nitrogen source until growth stopped completely. Then, excess ammonium sulphate was added, and the growth rate of the cells was followed for several additional hours. The addition of ammonia brought about an immediate increase in the growth rate of both the wild type and strain $\mathrm{K}$ (data not shown). As the growth of both strains was nearly identical, apparently $g \mathrm{lnK}^{+}$was not required for the shift from nitrogen-limiting to nitrogen excess conditions (data not shown).

Strain $\mathrm{KL} \phi$ contains null mutations in $g / n K$ and $g / n L$, as well as the $g \ln K:: / a c Z$ fusion. The expression of $g \ln A$ and glnK::lacZ in this strain was similar to that observed with $L \phi$, but there was less adenylylation of GS in nitrogenlimiting medium than was observed with $L \phi$ (Table 1).

The doubly mutant strain BK displays a severe growth defect on nitrogen-rich minimal medium

We constructed strain BK, containing null mutations in glnB and glnK, by our usual methods, which involve selection for drug-resistance markers on rich LB medium after P1-mediated generalized transduction (Experimental procedures). The doubly mutant BK strain grew well on rich LB medium, like the rest of the strains, but displayed a severe growth defect on solid defined media. Best growth was observed on the nitrogen-limiting glucose-arginine medium. There was some variability in the growth of strain BK on nitrogen-rich defined medium at the position where a heavy innoculum was placed onto the media, but in all cases single-colony isolates were not obtained. We attempted to measure GS expression and adenylylation in the double mutant, but the growth defect in liquid minimal media was even more severe than that observed with solid medium. In one experiment, duplicate cultures grew very slowly, and never reached the cell density usually used in the experiment $\left(O D_{600} 0.5\right)$, these were harvested at OD 0.1. In another experiment, duplicate cultures grew slowly to $\approx$ OD 0.1 , and then shot up to OD 0.5 . It seems likely that additional mutation(s) suppressing the growth defect were accumulated in these cultures during the experiments. Nevertheless, these cultures always contained elevated GS, which appeared to be almost completely adenylylated (data not shown). In two other attempts to repeat this experiment, strain BK failed to grow at all in liquid minimal medium. Thus, it is clear that the combination of $g \ln B$ and $g \ln K$ mutations in an otherwise wild-type background resulted in a severe growth defect in minimal medium.

The combination of the glnB and glnK mutations was epistatic to $\mathrm{g} \ln \mathrm{D}$

Although strain BK grew poorly even on the severely nitrogen-limiting glucose-arginine medium compared with the wild type, it grew considerably better than strain $\mathrm{BD}$, which essentially did not grow at all. We introduced the glnK null mutation into strain $\mathrm{BD}$; the resulting strain BDK had growth properties similar to strain BK, some ability to grow on minimal medium with arginine as the nitrogen source and a severe growth defect on nitrogen-rich minimal media. Thus, by reconstruction, in strain BD the $g / n K^{+}$ gene product was at least partially responsible for preventing growth on glucose-arginine medium, and was necessary to permit good growth on the other defined media tested.

A null mutation in gInL was epistatic to the combination of glnB and glnK mutations for the growth defect on minimal medium and for expression of Ntr genes but was not epistatic for the defect in GS adenylylation control

The severe growth defect of the BK strain was ameliorated upon introduction of a null mutation in $g / n L$. The triply mutant BKL strain ( $g \ln K \Delta g \ln B \Delta g \ln L 2001)$ had a growth phenotype similar to the singly mutant $g \ln L$ strain, indicating that for this phenotype $g / n L$ is epistatic to loss of both $g \ln B$ and $g \operatorname{lnK}$. Strain BKL $\phi$ contains null mutations in $g \ln B, g \ln K$ and $g \ln L$, as well as the $g \ln K:: / a c Z$ fusion. In this strain, GS expression was elevated on both nitrogenrich and nitrogen-limiting medium, and GS was very highly adenylylated regardless of nitrogen availability. Also, the glnK::lacZ fusion was induced to one-third of the wildtype level under inducing conditions and was expressed about 11-fold higher than in the wild type under repressing conditions, resulting in approximately sevenfold regulation by nitrogen availability. Thus, in strain BKL $\phi$, the glnL null mutation was epistatic for the growth defect and for the regulation of $g \ln A$ and $g \ln K$ but was not epistatic for the

(C) 1998 Blackwell Science Ltd, Molecular Microbiology, 29, 431-447 
GS adenylylation state defect resulting from the combination $\Delta g \ln B g \ln K$, as expected. However, it is curious that the expression of both $g \ln A$ and $g \ln K:: / a c Z$ were considerably elevated over the levels observed with strains $L \phi$, $\mathrm{BL} \phi$ and $\mathrm{KL} \phi$. As this strain grew well, the presence of a high intracellular concentration of GS-AMP was apparently not toxic.

The elevated expression of $g \ln A$ and $g \ln K:: / a c Z$ in strain $\mathrm{BKL} \phi$ was in part due to the presence of the wild-type $g \ln E$ gene, encoding ATase. Strain BLEK contains null mutations in $g \ln B, g \ln L, g \ln E$ and $g \operatorname{lnK}$. (An analogous strain with the glnK::lacZ fusion could not be constructed due to a lack of unique drug resistance selectable markers.) In strain BLEK, GS expression more closely resembles that seen in strain YMC10, and the GS is mostly unadenylylated (Table 1). The glnE mutation that we used should be null (Experimental procedures). The appearance of residual adenylylation in this strain may be due to a small difference in the activity of unadenylylated GS in the $\mathrm{Mn}^{2+}$ and $\mathrm{Mg}^{2+}$ assays, or may indicate the presence of an unknown enzyme that has ATase activity. To test whether the expression of GS was due to acetyl phosphate in this strain, we constructed strain BLEKP, which also lacks the capacity to form acetyl phosphate because of deletion of the pta-ackA portion of the chromosome. Strain BLEKP had very low levels of GS in both nitrogenlimiting and nitrogen excess conditions, as expected (Table 1). Thus, by comparing our results for strains BLK, BLEK and BLEKP, it is apparent that glnE has a role in this background in regulating the level of acetyl phosphate. This possibility was examined further by comparing strains $\mathrm{L} \phi$, LP $\phi, \mathrm{P}_{\phi}$ and LE $\phi$ (Table 1). Comparison of $\mathrm{L} \phi$ and $\mathrm{LP} \phi$ indicated that the expression of $g \ln A$ and the $g \ln K:: / a c Z$ fusion in $L \phi$ were due to acetyl phosphate (Table 1). In LE $\phi, g \ln A$ and $g \ln K:: / a c Z$ expression were clearly nitrogen regulated and higher than in strain L $\phi$ (Table 1). Thus, under certain circumstances, glnE was a regulator of acetyl phosphate accumulation.

The growth defect of strain BK seemed to be due to overexpression of one or more Ntr genes

As the gInL null mutation suppressed the growth defect associated with the combination of $g \ln B$ and $g \operatorname{lnK}$ null mutations; the growth defect of strain BK may be due to the unregulated action of the glnL product, NRII, driving expression of the Ntr regulon. We observed that the growth defect of strain BK was eliminated when a null mutation in $g \ln A$ was introduced, as long as glutamine was then provided. The $g \ln A:: \operatorname{Tn} 5$ mutation not only eliminates GS activity but also results in a decreased intracellular concentration of NRI and NRII because of polarity (Reitzer and Magasanik, 1986). Although the regulation of $g \ln A$ in trans is normal in such a strain, the cells are unable to increase the concentration of NRI by activation of the glnAp2 promoter (Pahel et al., 1982) and thus cannot accumulate $\mathrm{NRI} \sim \mathrm{P}$ to the level necessary for Ntr gene expression. Our result with the $g \ln A:: \operatorname{Tn} 5$ mutation thus did not distinguish whether the growth defect was due to $g \ln A$ or another nitrogen-regulated gene, but did indicate that by preventing expression of both $g \ln A$ and the Ntr regulon the ability to grow on minimal medium was restored.

We also examined the effect of introducing the $g \ln G:: \operatorname{Tn} 5$ mutation into strain BK. This mutation, eliminating NRI, renders the cell $\mathrm{Ntr}^{-}$, but does not cause glutamine auxotrophy unless combined with glnB (Bancroft et al., 1978; Bueno et al., 1985). The glnG::Tn5 mutation reduces the expression of $g \ln A$ greatly, but does not eliminate it. However, in cells containing a low amount of GS, over-adenylylation of GS such as in the $g \ln B g \ln G$ strain renders the cells glutamine auxotrophs, and suppressing mutation mapping in glnE (encoding ATase) may compensate for this defect (Bancroft et al., 1978). Studies with the purified ATase indicated that PII was not required for the adenylylation reaction, but PII UMP was required for the deadenylylation of GS AMP (reviewed in Rhee et al., 1985). That is, in the absence of regulation by PII and PII UMP, the ATase has a bias to adenylylate GS. As the expression of $g / n K$ is nitrogen regulated and dependent on $g \ln G$ (van Heeswijk et al., 1996), we may reinterpret the previous observation of GS overadenylylation in the $g \ln B g \ln G$ strain and the resulting glutamine auxotrophy as a result of the simultaneous absence of GInK and PII. Strain GBK, although also phenotypically a glutamine auxotroph, grew considerably better than strain BK on minimal media containing glutamine. This indicates that expression of the $\mathrm{Ntr}$ regulon in strain $\mathrm{BK}$ is at least partly responsible for the growth defect on nitrogen-replete minimal media.

As a further test of whether unregulated Ntr gene expression was responsible for the growth defect of strain $\mathrm{BK}$, we introduced the pBR322-based $g / n G^{+}$plasmid pgln31 into strain GBK (Backman et al., 1983). This plasmid, lacking an obvious promoter for $g / n G^{+}$, results in a constitutive very low level of NRI. This concentration of NRI is sufficient for normal regulation of $g \ln A$, but is not sufficient for full expression of Ntr genes. The resulting strain GBK/ pgln31 grew well on nitrogen-rich minimal medium. Thus, limiting the intracellular $\mathrm{NRI} \sim \mathrm{P}$ concentration suppressed the growth defect resulting from the combination of $g \ln B$ and glnK null mutations.

\section{The growth defect of strain BK can be ameliorated by addition of amino acids to minimal medium}

As several Ntr genes are involved in the catabolism of amino acids as nitrogen sources, one possible explanation for the growth defect of the doubly mutant BK strain is that constitutive expression of the Ntr system results in an amino 


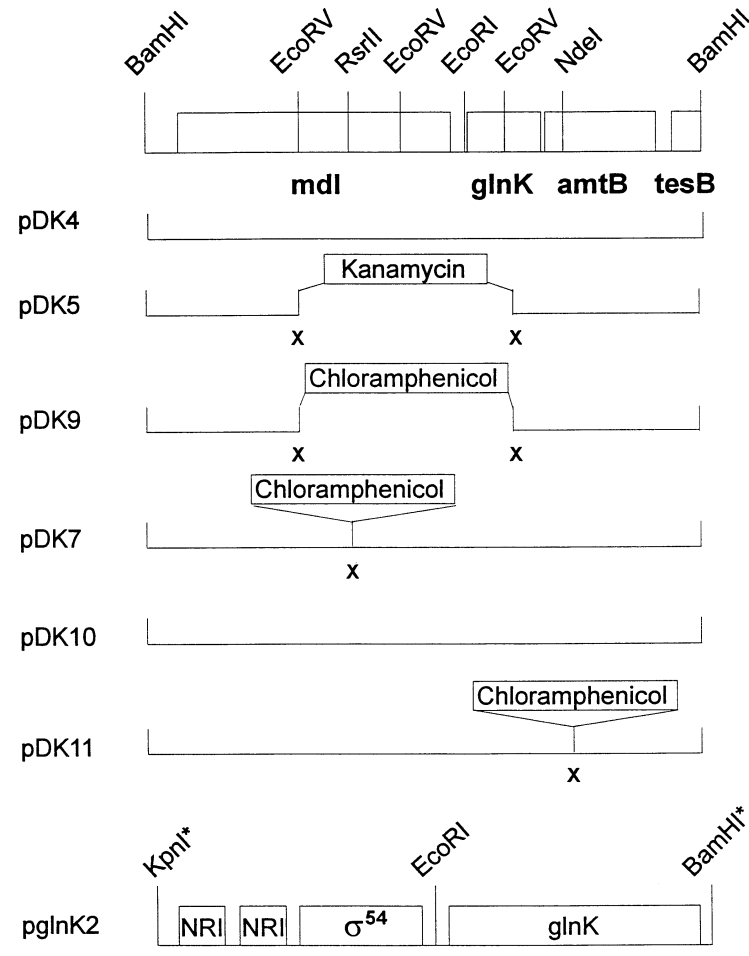

Fig. 2. Construction of $g / n K, m d l$ and $a m t B$ null mutations in vitro. The $10.1 \mathrm{~min}$ region of the $E$. coli chromosome is depicted at the top, along with the positions of the restriction cleavage sites used in this study. $\times$ indicates restriction sites destroyed as part of the cloning process. An asterisk is used to indicate sites introduced by our manipulations. At the bottom of the figure, the structure of the insert in pglnK2 is shown.

acid requirement. We observed that no single amino acid, when added to minimal medium, could restore to strain BK the ability to grow well. Also, the combination of arginine, proline and histidine, which are degraded by the hut, put and aut Ntr genes present in these cells, could not restore to BK the ability to grow on minimal medium. However, strain BK grew well on minimal medium supplemented with a complex mixture of amino acids, casein hydrolysate, to $0.1 \%(\mathrm{w} / \mathrm{v})$. This suggests that catabolism of several amino acids in strain BK may be the cause of the growth defect.

The $\mathrm{mdl}$ and amtB genes play no obvious role in nitrogen regulation

As the glnK mutation in strain BK in also $m d l$, and may be polar on expression of $a m t B$, it is unclear from the results described above whether the effects attributed to gInK were due to the absence the glnK product, amtB product, $m d l$ product or all of these gene products. We conducted several tests to see whether $m d l$ or amtB had a role in nitrogen regulation and whether these genes had a role in the growth defect observed when the glnK null mutation was combined with $\Delta g \ln B$. We compared nitrogen regulation of $g \ln A$ expression in the $m d l$ and $a m t B$ strains with the wild type and several control strains $(g \ln B, g \ln D, g \ln L)$. These experiments indicated that the expression of GS in the $m d l$ and $a m t B$ strains seemed to be wild type (data not shown). We also constructed strains that were $\Delta g \ln B$ and null for either $a m t B$ or $m d l$ but were $g l n K^{+}$ (strain BX and strain BM respectively). These strains grew as well as the $\Delta g \ln B$ strain on all media tested, indicating that the combination of $\Delta g \ln B$ with either $a m t B$ or $m d l$ did not result in a growth defect. Finally, we transformed strain BK with multicopy plasmids encoding either glnB ${ }^{+}$(pBUC10; Jiang et al., 1997), glnK ${ }^{+}$(pglnK2; Fig. 2), or glnK $^{+} a m t B^{+}$(pDK10; Fig. 2). In all three cases, the transformants were able to grow well on nitrogen-rich minimal media, suggesting that $a m t B$ and $m d /$ had little role, if any, in the growth defect. This experiment also indicated that the presence of either PII or GInK was sufficient to permit growth on nitrogen-rich minimal medium. In addition, we transformed strain BK with plasmid pBB180, which is identical to $\mathrm{pBUC} 10$ but contains a point mutation resulting in the alteration A49P in PII. This mutation in gInB was previously selected as defective in the negative regulation of $g \ln A$ expression, and work with the purified protein indicated that it was uridylylated normally and interacted with the ATase well but could not interact with NRII (Jiang et al., 1997). Transformation of strain BK with pBB180 resulted in poor complementation for growth on nitrogenrich defined solid media. This result suggests that NRII must be properly controlled for growth on these media, and thus that GlnK must be involved in regulation of NRII in cells lacking PII.

\section{Either glnB or glnK can regulate GS adenylylation state and gInA expression}

The regulation of $g \ln A$ expression and the GS adenylylation state were examined in transformants of strains $B K$ and $\mathrm{B}$ containing pglnB ${ }^{+}(\mathrm{pBUC10})$ and pglnK2 (Table 3). The presence of $\mathrm{pBUC10}$ in either of these strains resulted in the inability to induce fully $g \ln A$ in nitrogen-limiting medium, as previously described (Jiang et al., 1997), but the regulation of GS adenylylation was essentially normal. The pBUC10 plasmid caused the massive overexpression of PIl (Jiang et al., 1997). In contrast, the presence of pglnK2 resulted in the normal regulation of GS adenylylation, as well as good regulation of $g \ln A$ expression (Table $3)$. Although the pglnK2 plasmid did not vastly hyperexpress GlnK, as deduced by examining crude extracts on gels (data not shown), it is likely that the level of GlnK in these transformants is higher than typically found in wild-type cells. These results therefore suggest that, at least under these conditions, GlnK could interact with the ATase to bring about regulation of GS adenylylation state

(C) 1998 Blackwell Science Ltd, Molecular Microbiology, 29, 431-447 
and could interact with NRII to bring about regulation of $g \ln A$ expression. The fact that $g \ln A$ expression was regulated in response to ammonia when GInK was present suggests that signalling occurred via the reversible covalent modification of GInK by the glnD-encoded UTase/ UR, in agreement with earlier observations (van Heeswijk et al., 1996).

The results shown in Tables 1 and 3 suggested that either GInK or PII was sufficient for the regulation of GS adenylylation state. As the cultures used in these experiments were adapted to the growth medium, no information is provided about the kinetics of the regulation of GS adenylylation. We examined the kinetics of GS adenylylation in response to ammonia shock in strains lacking either GlnK or PII. For these experiments, cultures were adapted to nitrogen-limited conditions and had a low level of GS adenylylation. Upon shock with ammonia, both strain $B$ and strain $\mathrm{K}$ rapidly adenylylated GS, with the same rate of adenylylation as the wild-type strain (data not shown). This result is consistent with the hypothesis that either GInK or PII is sufficient for proper adenylylation state regulation, and furthermore suggests that the reversible modification of both proteins in vivo is rapid.

The amtB gene does not seem to be involved in ammonium transport

The $a m t B$ gene shares some homology with the $a m t B$ gene of yeast, which is thought to be involved in ammonia transport. Thus, it was proposed that amtB may have a similar role in bacteria (van Heeswijk et al., 1996). We examined whether $a m t B$ and/or glnK had a role in facilitating growth on ammonia at low concentration by streaking out the wildtype strain, strain $\mathrm{K}$ (lacking glnK and probably also amtB because of polarity) and the strain lacking only amt $B$ on a series of plates containing decreasing concentrations of ammonia. The result of this experiment was that no discernible difference in growth was observed, suggesting no obvious role for $g / n K$ and/or amtB in ammonia transport.

Spontaneous supressor mutations allowing strain $B D$ to use arginine as the sole nitrogen source map in glnK and result in GlnK proteins with altered function

Previous experiments have indicated that spontaneous supressor mutations permitting strain D ( $g \ln D 99:: \operatorname{Tn} 10)$ to use arginine as nitrogen source can occur in $g / n L$ (ntrB) (McNeil et al., 1982a,b; Atkinson and Ninfa, 1992), and some of these affect the interaction of NRII with PII (Atkinson and Ninfa, 1992). Mutations in $\operatorname{glnG}(n t r C)$ encoding altered NRI proteins that are better transcription activators or that activate transcription in the absence of phosphorylation can also suppress the $\mathrm{Ntr}^{-}$phenotype of strain $\mathrm{D}$ (McNeil et al., 1982b; Weglenski et al., 1989; Flashner et al., 1995). Although strain BD could not use arginine as a nitrogen source, spontaneous mutations that restore this ability could be readily selected. Transductional mapping of these supressor mutations revealed that most of them were linked to the $\operatorname{gInALG}$ operon; that is, when the suppressor strains were used as the donor to introduce the $g \ln A L G$ region into a wild-type background, elevated $g \ln A$ expression in the presence of ammonia was observed (data not shown). These suppressor mutations probably map to $g / n L$ and/or $g / n G$, and correspond to the classes of suppressing mutations observed previously. To avoid these $g \ln A$-linked supressors, we transformed strain BD with either pgln2, which contains the entire wild-type gInALG operon in pBR322 and modestly overexpresses all three gene products (Backman et al., 1981), or pgln62, which contains only $\mathrm{glnL}^{+}$in pBR322 (Ueno-Nishio et al., 1984) and modestly overexpresses NRII (Atkinson and Ninfa, 1993). The BD transformants containing these plasmids were observed to be unable to use arginine as a nitrogen source and to throw off variants that were able to use arginine as a nitrogen source, like their parent. To determine if these variants contained extragenic suppressors in $g / n K$, we crossed them with a donor phage grown on a strain containing $m d l:: k a n$, with selection for kanamycin resistance. As $m d l$ is tightly linked to $g / n K$ in transductional crosses, introduction of the $m d l$ marker should simultaneously result in the introduction of $\mathrm{glnK}^{+}$, and this should eliminate the suppression if the suppression were due to mutations in $g / n K$. The results of these experiments were that 5 out of 10 suppressed strains examined contained suppressing mutations closely linked to mdl. The DNA sequence of the glnK gene from the five strains containing putative $g$ InK mutations was examined by direct sequencing from the bacterial chromosome after PCR amplification (Experimental procedures). Each of these five strains was observed to contain a point mutation in the glnK coding sequence altering a single amino acid, as indicated in Table 4. Interestingly, three of the five glnK mutations resulted in three different alterations of residue arginine-47 of GlnK. Thus, consistent with the results already presented, $g / n K^{+}$appears to be responsible for the inability of strain $\mathrm{BD}$ to use arginine as a nitrogen source.

We used another method to simplify the identification of extragenic suppressors of strain BD that map in $g / n K$, and to simplify the transfer of these mutations to other strains. We constructed strain BDM by crossing $m d l:: c h /$ into strain $\mathrm{BD}$. As expected, mutation of the mal gene had no significant effect on the phenotype of strain BD (Table 1 and data not shown). Spontaneous extragenic suppressors permitting strain BDM to grow on arginine as a sole nitrogen source were then isolated by direct selection, and transducing phage lysates were prepared on these strains. The phage were then used to backcross the mdl marker, 
Table 4. glnK point mutants.

\begin{tabular}{|c|c|c|c|}
\hline Strain & Allele & $\begin{array}{l}\text { Alteration } \\
\text { in GInK }\end{array}$ & $\begin{array}{l}\text { DNA sequence } \\
\text { change }\end{array}$ \\
\hline \multicolumn{4}{|l|}{ Selection: BD/p62 $\rightarrow$ glucose-arginine +} \\
\hline OB14 & $g \ln K 2$ & $\mathrm{R} 47 \rightarrow \mathrm{L}$ & $\mathrm{CGG} \rightarrow \mathrm{CTG}$ \\
\hline OB22 & $g \ln K 3$ & $\mathrm{E} 44 \rightarrow \mathrm{G}$ & $\mathrm{GAC} \rightarrow \mathrm{GGG}$ \\
\hline OB25 & $g \ln K 4$ & $\mathrm{R} 47 \rightarrow \mathrm{W}$ & $\mathrm{CGG} \rightarrow \mathrm{TGG}$ \\
\hline \multicolumn{3}{|l|}{ Selection: BD/pgln2 $\rightarrow$ glucose-arginine +} & $\mathrm{TAC} \rightarrow \mathrm{AAC}$ \\
\hline \multicolumn{4}{|l|}{ Selection: BDM $\rightarrow$ glucose-arginine +} \\
\hline $\begin{array}{l}\mathrm{KM} 4 \\
\mathrm{KM} 14\end{array}$ & $\begin{array}{l}g \ln K 6 \\
g \ln K 7\end{array}$ & $\begin{array}{l}\mathrm{Y} 46 \rightarrow \mathrm{C} \\
\mathrm{F} 11 \rightarrow \mathrm{I}\end{array}$ & $\begin{array}{l}\mathrm{TAC} \rightarrow \mathrm{TGC} \\
\mathrm{TTC} \rightarrow \mathrm{ATC}\end{array}$ \\
\hline KM25 & $g \ln K 8$ & $\mathrm{R} 47 \rightarrow \mathrm{W}$ & $\mathrm{CGG} \rightarrow \mathrm{TGG}$ \\
\hline KM28 & $g \ln K 9$ & $\mathrm{R} 47 \rightarrow \mathrm{L}$ & $\mathrm{CGG} \rightarrow \mathrm{CTG}$ \\
\hline KM31 & $\operatorname{glnK} 10$ & $\mathrm{Y} 46 \rightarrow \mathrm{C}$ & $\mathrm{TAC} \rightarrow \mathrm{TGC}$ \\
\hline
\end{tabular}

and tightly linked glnK gene, into strain $\mathrm{BD}$, and the ability of the transductants to grow on glucose-arginine was assessed. Of 28 suppressed strains examined in this way, five contained suppressor mutations linked to $m d l$. DNA sequencing of the five $\mathrm{mdl}$-linked suppressors indicated that in all cases the glnK gene was altered, as shown in Table 4. Interestingly, two of the mutations resulted in the same GlnK alterations (R47 $\rightarrow \mathrm{W}, \mathrm{R} 47 \rightarrow \mathrm{L}$ ) obtained from the selection performed in strain $\mathrm{BD} / \mathrm{pg} \ln 62$.

To determine if the glnK point mutations obtained as suppressors of strain BDM were null, we examined whether these strains exhibited the severe growth defect on minimal medium that was observed with strain $\mathrm{BK}$ and strain BDK. The BDM-based strains containing glnK6 (which is identical to glnK10) had a growth defect, and strains containing gInK 7 had a very severe growth defect, reminiscent of strain BDK and BK. Thus, it is possible that $g \ln K 7$ is a null allele and $g I n K 6$ encodes a product with low activity. In contrast, the strains containing gInK8 and gInK 9 displayed no apparent growth defect on nitrogen-rich minimal medium. This phenotype suggests that these $g / n K^{*}$ alleles are not null, but rather encode products that interact with NRII less well than does wild-type GlnK.

To assess the effects of the $g / n K^{*}$ mutations on the expression of the $g / n K:: / a c Z$ fusion, we constructed strains BDMK* $\phi$ containing the $g / n K 8$ and $g / n K 9$ alleles. In all cases, the expression of $g \ln A$ was similar to strain BDM but the expression of the $g I n K:: / a c Z$ fusion was greatly elevated under both nitrogen-limiting and nitrogen excess conditions (Table 1). This result indicated that in strain $\mathrm{BDM} \phi$, GInK plays a role in negative regulation of the gInK promoter.

To assess the phenotype resulting from the $g / n K^{*}$ mutations in the presence of $g \ln D^{+}$, we constructed BK* strains containing the $g / n K 8$, and $g / n K 9$ alleles. Strains lacking PII and containing glnK8 and glnK9 alleles grew well, again indicating that these glnK alleles are not null. The normal regulation of GS adenylylation state in these strains indicated that these GInK proteins are able to productively interact with the ATase and UTase/UR (Table 2).

\section{Discussion}

Our work indicates that $g \ln K$ has a role in nitrogen regulation, and that at least part of this role is to bring about the repression of Ntr gene expression by acting through the gInL product, NRII to control the level of NRI $\sim$ P. Although much remains to be learned, it is clear from our results and previous results that $g \ln K$ and $g \ln B$ have only partially overlapping functions. For example, in adapted liquid cultures the absence of GInK had only a minor effect on $g \ln A$ expression, whereas the absence of PII resulted in the loss of negative regulation by ammonia, as noted earlier (Bueno et al., 1985). Thus, GlnK and PII are not interchangeable. On the other hand, the regulation of the adenylylation of GS was essentially normal in strains lacking either PII or GlnK (van Heeswijk et al., 1996, this work), suggesting that either protein may suffice for this regulation.

Several lines of evidence indicated that GlnK acts through NRII to control the level of NRI P. In the aggregate, the data suggested that GlnK was less effective than was $\mathrm{PII}$ in reducing the level of $\mathrm{NRI} \sim \mathrm{P}$, and thus had little effect on expression from the glnAp2 promoter, which is extraordinarily sensitive to NRI P. However, GlnK plays an important role in the regulation of Ntr promoters that require a higher concentration of $\mathrm{NRI} \sim \mathrm{P}$ for activation. One such promoter is the glnK promoter, which apparently requires a higher intracellular concentration of NRI $\sim P$ for activation than does the glnAp2 promoter. The $g \ln D 99:: \operatorname{Tn} 10$ mutation, which is known to be leaky (Atkinson and Ninfa, 1992), had a relatively modest effect on the induction of $g \ln A$ by nitrogen limitation, although this mutation essentially eliminated expression from the $g / n K$ promoter. Also, glnK was not highly expressed in strain $\mathrm{BD}$, whereas $g \ln A$ was highly expressed. Our results indicated that GlnK was responsible for regulation of the $g I n K$

(C) 1998 Blackwell Science Ltd, Molecular Microbiology, 29, 431-447 
promoter in cells lacking $\mathrm{PII}$, and this regulation was reduced by the $g \ln K 8$ and $g \ln K 9$ mutations.

The role of GInK in regulating the expression of other Ntr genes is suggested by the properties of the double mutant lacking both PII and GInK. This strain cannot grow on defined medium, but this defect was ameliorated by further loss of NRII, NRI or by genetic manipulations that limited the intracellular concentration of NRI. Thus, the growth defect of the double mutant is apparently due to unregulated expression of one or more Ntr genes. As many Ntr genes are involved in the catabolism of amino acids, this conclusion is consistent with the observation that the growth defect could be eliminated by supplementation with a complex mixture of amino acids. Because the strain lacking only PII does not display a similar growth defect, it is clear that GInK has a role in the regulation of Ntr gene expression, and this role is by acting through NRII and NRI.

Previous structural studies of PII have indicated that the protein contains a large loop (the T loop) that contains the site of uridylylation and is probably the site of interaction with NRII and ATase (Carr et al., 1996). This hypothesis is consistent with structure/function studies indicating that the $\mathrm{T}$ loop is required for interaction with the receptors and that mutations altering PII receptor specificity mapped there (Jiang et al., 1997). For example, alteration of residue alanine 49 of PII resulted in an altered protein that interacted normally with the ATase, UTase, and small molecule effectors, but did not interact with NRII. In the current work, we observed that alteration of arginine-47 of GlnK altered the negative regulation of gene expression by GInK (i.e. its interaction with NRII) while apparently not altering significantly the regulation of GS adenylylation state (indicating interaction with the UTase/UR and ATase). The arginine47 residue seems to be particularly interesting, as 5 of the first 10 sequenced $g / n K^{*}$ mutations altered this residue. It is likely that good growth under the selective conditions required both the retention of ability to regulate the ATase and a decrease in the interaction with NRII, and that relatively few random mutation satisfy these criteria.

The existence of structurally similar but functionally distinct PII proteins has been previously observed in Azospirillum brasilense (de Zamaroczy et al., 1996) and may be a common theme in bacteria. What regulatory advantage is obtained by having slightly different versions of the PII protein with the expression of one regulated by the other? One possibility is that the cells contain additional receptors that are specifically controlled by GInK or GInK UMP, thus forming a regulatory cascade. Although this may be so, our results indicate that GInK had a role in regulating the level of phosphorylation of NRI. GInK may act as a 'memory protein' as proposed by van Heeswijk et al. (1996). If so, then additional experiments in which cells are shifted between various conditions may reveal an advantage conferred by the presence of GInK. Our results indicated that GInK was not required to efficiently shift from a condition of nitrogen limitation to a condition of nitrogen excess. However, whether GInK confers an advantage to nitrogen-starved cells that encounter transitory increases in ammonia remains to be investigated. Additional possibilities are that GlnK serves to uncouple the regulation of NRII from the regulation of ATase under conditions of nitrogen limitation, that GInK simply acts as a governor preventing sustained full expression of certain Ntr genes under all conditions or that GInK is required for the fine control of $\mathrm{NRI} \sim \mathrm{P}$ levels when these are near the upper end of the physiological range. Many other hypotheses are possible, and experiments with purified components are required to reduce the range of possibilities.

Our experiments with strains lacking NRII unexpectedly revealed an inverse correlation between the level of glutamine synthetase activity and the level of acetyl phosphate accumulation under certain conditions. The acetyl phosphate pool may be influenced by the acetyl CoA pool, which is in turn influenced by the rate of glycolysis and tricarboxylic acid (TCA) cycle reactions (reviewed by McCleary et al., 1993). As one substrate for GS is glutamate, derived from 2-ketoglutarate, high GS activity may drain TCA cycle intermediates and reduce the intracellular acetyl phosphate (McCleary et al., 1993). In the absence of GS activity, the accumulation of acetyl phosphate may be favoured. This hypothesis is consistent with our observation that a mutation affecting ATase $(g \ln E)$, which controls GS activity in cells, appears to affect acetyl phosphate accumulation under some circumstances. In strain BKL, GS is always highly adenylylated, and consequently GS activity is low. The overadenylylation of GS in this strain is probably because of the bias of ATase to adenylylate GS in the absence of regulation. The low GS activity in strain BKL is somehow compensated for by an increase in acetyl phosphate, as revealed by very high expression of $g \ln A$. In contrast, strain BKLE lacks the ability to adenylylate GS and consequently has higher GS activity. This is somehow compensated for by decreased accumulation of acetyl phosphate, as revealed by a reduced activation of $g \ln A$ as compared with strain $\mathrm{BKL}$. If this correlation indicates that GS activity influences acetyl phosphate accumulation, then it may be predicted that in cells lacking NRII and ATase, point mutations in glnA reducing GS catalytic activity should result in increased acetyl phosphate and thus increased expression of $g \ln A$.

\section{Experimental procedures}

\section{Bacteriological techniques}

Rich L-broth + glutamine medium and defined media were as described previously (Atkinson and Ninfa, 1992). Generalized transduction was as described using P1vir (Silhavy et al., 1984). Transformation with plasmid DNA was performed as 
Table 5. Strains and plasmids used in this study.

\begin{tabular}{|c|c|c|}
\hline Strain & Relevant genotype & Source or construction \\
\hline YMC10 & Wild-type & Backman et al. (1981) \\
\hline G & $g \ln G:: \operatorname{Tn} 5$ & Backman et al. (1981) \\
\hline B & $\Delta g \ln B$ & Bueno et al. (1985) \\
\hline D & $g \ln D 99:: \operatorname{Tn} 10$ & Bueno et al. (1985) \\
\hline L & $g \ln L 2001$ & Bueno et al. (1985) \\
\hline A & $g \ln A:: \operatorname{Tn} 5$ & Reitzer and Magasanik (1986) \\
\hline BA & $\Delta g \ln B g \ln A:: \operatorname{Tn} 5$ & Feng et al. (1992) \\
\hline $\mathrm{BL}$ & $\Delta g \ln B g \ln L 2001$ & Feng et al. (1992) \\
\hline RB9017 & $g \ln E:: \operatorname{Tn} 5$ & Bueno et al. (1985) \\
\hline $\mathrm{BD}$ & $\Delta g \ln B \operatorname{gln} D 99:: \operatorname{Tn} 10$ & RB9060 $\times$ RB9040P1vir \\
\hline BDL & $\Delta g \ln B$ glnD99::Tn 10 glnL2001 & BL $\times$ RB9040 P1vir \\
\hline MW1 & $\Delta g \ln B . . \operatorname{Tn} 5 c h l^{r}$ & Laboratory collection \\
\hline K4633 & $\operatorname{rec} D$ & David Friedman \\
\hline MAE & $\operatorname{rec} D \operatorname{gln} E 3:: \mathrm{ch}^{\mathrm{r}}$ & $\mathrm{K} 4633 \times \mathrm{pg} \ln E 3 \mathrm{DNA}$ \\
\hline MAK & $r e c D \Delta m d l-g \ln K:: k a n^{r}$ & K4633×pDK5 DNA \\
\hline MAKc & recD $\Delta m d l-g \ln K:: c h l^{\mathrm{r}}$ & K4633×pDK9 DNA \\
\hline MAM & $r e c D m d l:: c h l^{r}$ & K4633 × pDK7 DNA \\
\hline MAAmtB & $r e c D$ amtB::chlr & $\mathrm{K} 4633 \times \mathrm{pDK} 11 \mathrm{DNA}$ \\
\hline $\mathrm{K}$ & $\Delta m d l-g \ln K:: k a n^{r}$ & YMC10×MAK P1vir \\
\hline BK & $\Delta g \ln B \Delta m d l-g \ln K:: k a n^{r}$ & RB9060×MAK P1vir \\
\hline BKc & $\Delta g \ln B \Delta m d l-g \ln K:: c h l^{r}$ & RB9060 ×MAKc P1vir \\
\hline BG & $\Delta g \ln B g \ln G:: \operatorname{Tn} 5$ & YMC12×MW1 P1vir \\
\hline GBK & $\Delta g \ln B \Delta m d l-g \ln K:: c h l^{r} g \ln G:: \operatorname{Tn} 5$ & $\mathrm{BKc} \times \mathrm{YMC} 12 \mathrm{P} 1 \mathrm{vir}$ \\
\hline GKc & $g \ln G:: \operatorname{Tn} 5 \Delta m d l-g \ln K:: c h l^{r}$ & YMC12×MAKc P1vir \\
\hline BDK & $\Delta g \ln B \Delta m d l-g \ln K:: k^{2} n^{r} g \ln D 99:: \operatorname{Tn} 10$ & BD $\times$ MAK P1vir \\
\hline $\mathrm{KA}$ & $\Delta m d l-g \ln K:: c h l^{r} g \ln A:: \operatorname{Tn} 5$ & TH16 $\times$ MAKc P1vir \\
\hline BKA & $\Delta g \ln B \Delta m d l-g \ln K:: c h l^{r} g \ln A:: \operatorname{Tn} 5$ & $\mathrm{BA} \times \mathrm{MAKc}$ P1vir \\
\hline BM & $\Delta g \ln B m d l:: \operatorname{chl}^{r}$ & B×MAM P1vir \\
\hline BDM & $\Delta g \ln B g \ln D 99:: \operatorname{Tn} 10 \mathrm{mdl}:: \mathrm{chl}^{\mathrm{r}}$ & $\mathrm{BD} \times \mathrm{MAM}$ P1vir \\
\hline $\mathrm{x}$ & amtB::chlr ${ }^{r}$ & YMC10×MAAmtB P1vir \\
\hline$B X$ & $\Delta g \ln B$ amtB ::chl ${ }^{r}$ & RB9060 $\times$ MAAmtBP1vir \\
\hline LK & $g \operatorname{lnL} 2001 \Delta m d l-g \operatorname{lnK}:: k a n^{r}$ & RB9132×MAK P1vir \\
\hline BLK & $\Delta g \ln B g \ln L 2001 \Delta m d l-g \ln K:: k a n^{r}$ & BL $\times$ MAK P1vir \\
\hline LE & gInL2001 gInE3:: chl ${ }^{r}$ & L×MAE P1vir \\
\hline BW1311 & w.t & B. L. Wanner \\
\hline BW18500 & $\Delta g \operatorname{lnL2001} \Delta$ pta-ackA..zej::Tn 10 & B. L. Wanner \\
\hline $\mathrm{P}$ & $\Delta$ pta-ackA..zej::Tn 10 & Feng et al. (1992) \\
\hline LP & $\Delta g \operatorname{lnL2001} \Delta$ pta-ackA..zej::Tn 10 & Feng et al. (1992) \\
\hline LEP & $\Delta g \ln L 2001 \Delta$ pta-ackA..zej::Tn $10 \mathrm{~g} \ln E 3:: \mathrm{chl}$ & LE $\times$ BW18500 P1vir \\
\hline BLEK & $\Delta g \ln B \Delta g \ln L 2001 \mathrm{~g} \ln E 3:: \mathrm{chl} \Delta m d l-g \operatorname{lnK}:: \mathrm{kan}^{r}$ & BLK $\times$ MAE P1vir \\
\hline BLEKP & $\Delta g \ln B \Delta g \ln L 2001$ glnE3::chl $\Delta m d l-g \operatorname{lnK}:: k a n^{r} \Delta p t a-a c k A . z e j:: T n 10$ & BLEK $\times$ BW18500 P1vir \\
\hline TE2680 & recD1903::Tn 10 trpDC700::putPA1303[Kan $\left.{ }^{s} \mathrm{Chl}^{r} / a c\right]$ & Elliott (1992) \\
\hline TE $\phi$ & recD1903::Tn 10 trpDC700::putPA1303[Kan $\left.{ }^{r} \mathrm{Chl}{ }^{\mathrm{s}} \mathrm{glnKp}-\mathrm{lac}\right]$ & TE2680 $\times$ pglnK3 DNA \\
\hline $\mathrm{B} \phi$ & 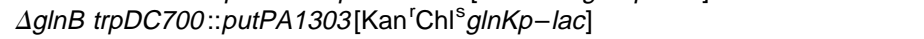 & $\mathrm{B} \times \mathrm{TE} \phi \mathrm{P} 1 \mathrm{vir}$ \\
\hline $\mathrm{BD} \phi$ & 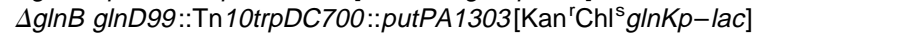 & $\mathrm{BD} \times \mathrm{TE} \phi \mathrm{P} 1 \mathrm{vir}$ \\
\hline $\mathrm{D} \phi$ & 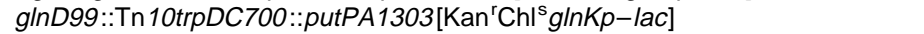 & $\mathrm{D} \times \mathrm{TE} \phi \mathrm{P} 1 \mathrm{vir}$ \\
\hline YMC10 $\phi$ & $\operatorname{trpDC700::putPA1303[\mathrm {Kan}^{\mathrm {r}}\mathrm {Chl}^{\mathrm {s}}\mathrm {g}\operatorname {ln}Kp-lac]}$ & YMC10 $\times$ TE $\phi$ P1 vir \\
\hline $\mathrm{L} \phi$ & 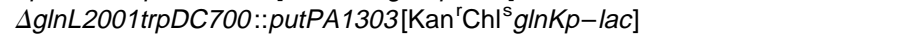 & $\mathrm{L} \times \mathrm{TE} \phi \mathrm{P} 1 \mathrm{vir}$ \\
\hline BL $\phi$ & 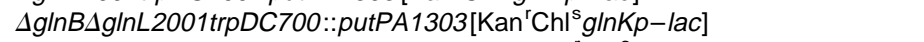 & $\mathrm{BL} \times \mathrm{TE} \phi \mathrm{P} 1 \mathrm{vir}$ \\
\hline LE $\phi$ & $\Delta g \operatorname{lnL} 2001 \mathrm{~g} \operatorname{lnE} 3::$ chltrpDC700::putPA1303[Kan $\left.{ }^{\mathrm{r}} \mathrm{Chl}{ }^{\mathrm{s}} \mathrm{g} \operatorname{lnKp}-\mathrm{lac}\right]$ & LE $\times$ TE $\phi$ P1vir \\
\hline $\mathrm{P} \phi_{\phi}$ & spta-ackA..zej::Tn 10trpDC700::putPA1303[Kan $\left.{ }^{\mathrm{r}} \mathrm{Ch} \mathrm{l}^{\mathrm{s}} \mathrm{g} \ln \mathrm{Kp}-\mathrm{lac}\right]$ & $\mathrm{P} \times \mathrm{TE} \phi \mathrm{P} 1 \mathrm{vir}$ \\
\hline LP $\phi$ & 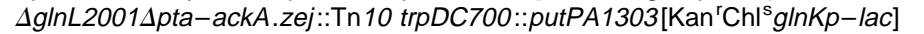 & LP $\times$ TE $\phi$ P1vir \\
\hline BLK $\phi$ & $\Delta g \ln B \Delta g \ln L 2001 \Delta m d l-g \operatorname{lnK}:: c h l^{r} \operatorname{trpDC700}:: p u t P A 1303\left[\mathrm{Kan}^{\mathrm{r}} \mathrm{Ch} l^{\mathrm{s}} g \ln K p-l a c\right]$ & BL $\phi \times$ MAKc P1vir \\
\hline $\mathrm{KL} \phi$ & 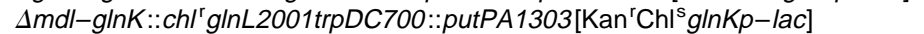 & L $\phi \times$ MAKc P1vir \\
\hline $\mathrm{K} \phi$ & 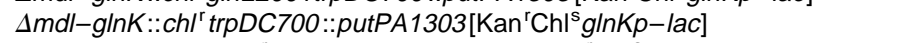 & YMC10 $\phi \times$ MAKc P1vir \\
\hline LEP $\phi$ & 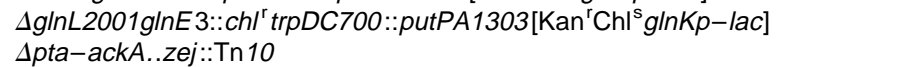 & LE $\phi \times B W 18500$ P1vir \\
\hline $\mathrm{BDM} \phi$ & 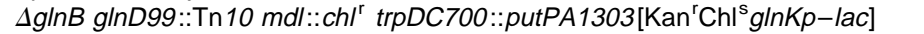 & $\mathrm{BDM} \times \mathrm{TE} \phi$ \\
\hline $\mathrm{BD} / \mathrm{pg} \ln 62$ & $\Delta g \ln B \operatorname{gln} D 99:: \operatorname{Tn} 10 \mathrm{pg} \ln 62\left(g \ln L^{+}\right)$ & $\mathrm{BD} \times \mathrm{pg} \ln 62$ \\
\hline OB10 & $\Delta g \ln B g \ln D 99:: \operatorname{Tn} 10 \mathrm{pg} \ln 62 \mathrm{~g} \ln K 1$ & $\mathrm{BD} / \mathrm{pgln} 62 \rightarrow \mathrm{Garg}^{+}$ \\
\hline OB14 & $\Delta g \ln B g \ln D 99:: \operatorname{Tn} 10 \mathrm{pg} \ln 62 \mathrm{~g} \ln K 2$ & $\mathrm{BD} / \mathrm{pg} \ln 62 \rightarrow \mathrm{Garg}^{+}$ \\
\hline OB22 & $\Delta g \ln B \operatorname{gln} D 99:: \operatorname{Tn} 10 \mathrm{pg} \ln 62 \mathrm{~g} \ln K 3$ & $\mathrm{BD} / \mathrm{pgln} 62 \rightarrow \mathrm{Garg}^{+}$ \\
\hline OB25 & $\Delta g \ln B$ glnD $99:: T n 10 p g \ln 62$ glnK4 & $\mathrm{BD} /$ pgln62 $\rightarrow$ Garg $^{+}$ \\
\hline $\mathrm{BD} / \mathrm{pg} \ln 2$ & $\Delta g \ln B g \ln D 99:: \operatorname{Tn} 10 \mathrm{pg} \ln 2\left(g \ln A L G^{+}\right)$ & $\mathrm{BD} \times \mathrm{pg} \ln 2$ \\
\hline OB113 & $\Delta g \ln B$ glnD $99:: \operatorname{Tn} 10 \mathrm{pg} \ln 2 \mathrm{~g} \ln K 5$ & $\mathrm{BD} / \mathrm{pgln} 2 \rightarrow \mathrm{Garg}^{+}$ \\
\hline KM4 & $\Delta g \ln B$ glnD $99:: \operatorname{Tn} 10 \mathrm{mdl}:: \mathrm{chl}^{\top} \mathrm{g} \ln K 6$ & $\mathrm{BDM} \rightarrow$ Garg + \\
\hline KM14 & $\Delta g \ln B$ glnD $99:: \operatorname{Tn} 10 \mathrm{mdl}::\left.\mathrm{ch}\right|^{\mathrm{r}} \mathrm{g} \ln K 7$ & $\mathrm{BDM} \rightarrow$ Garg + \\
\hline
\end{tabular}


Table 5. Continued.

\begin{tabular}{|c|c|c|}
\hline Strain & Relevant genotype & Source or construction \\
\hline KM25 & $\Delta g \ln B \operatorname{gln} D 99:: \operatorname{Tn} 10 \mathrm{mdl}:: \mathrm{chl}^{\mathrm{r}} \mathrm{g} \ln K 8$ & $\mathrm{BDM} \rightarrow$ Garg + \\
\hline KM28 & $\Delta g \ln B$ glnD99::Tn 10 mdl::chl'glnK9 & $\mathrm{BDM} \rightarrow$ Garg + \\
\hline KM31 & $\Delta g \ln B$ glnD99::Tn10 mdl:::chl' $\mathrm{g} \operatorname{lnK} 10$ & $\mathrm{BDM} \rightarrow \mathrm{Garg}+$ \\
\hline BK-6 & $\Delta g \ln B \mathrm{mdl}:: \mathrm{ch} / \mathrm{r} g \ln K 6$ & RB9060 KM4 P1vir \\
\hline BK-7 & $\Delta g \ln B m d l:: c h l^{\prime} g \ln K 7$ & RB9060 KM14 P1vir \\
\hline BK-8 & $\Delta g \ln B m d l:: c h l^{\prime} g \ln K 8$ & RB9060 KM25 P1vir \\
\hline BK-9 & $\Delta g \ln B m d l:: c h l^{r} g \ln K 9$ & RB9060 KM28 P1vir \\
\hline BDM $\phi g \ln K 8$ & 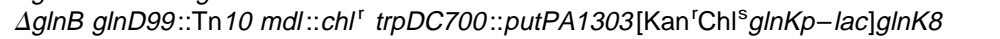 & KM25×TE $\phi$ P1vir \\
\hline BDM $\phi g \ln K 9$ & $\Delta g \ln B$ glnD99::Tn 10 mdl ::chl $l^{r}$ trpDC700::putPA1303[Kan $\left.{ }^{r} \mathrm{Chl}^{\mathrm{s}} \mathrm{g} \ln K p-l a c\right] g \ln K 9$ & KM28 $\times$ TE $\phi$ P1vir \\
\hline CAG12148 & tsx-247::Tn 10 (9.5 min) & Miller (1992), via Rowena Matthews \\
\hline CAG12154 & $\mathrm{zbb}-3055:: \operatorname{Tn} 10(11.5 \mathrm{~min})$ & Miller (1992), via Rowena Matthews \\
\hline CAG12107 & $\mathrm{zba}-3101:: \operatorname{Tn} 10 \mathrm{kan}(10.5 \mathrm{~min})$ & Miller (1992), via Rowena Matthews \\
\hline CAG12017 & zba-3054::Tn 10 (10.5 min) & Miller (1992), via Rowena Matthews \\
\hline Plasmid & Relevant genotype or construction & Source/reference \\
\hline $\begin{array}{l}\text { pUC18 } \\
\text { pUC18N }\end{array}$ & $\begin{array}{l}a_{m p}^{r} \text { cloning vector } \\
a^{r} \text {, pUC18, but unique Ndel site destroyed by filling in with Klenow and religation }\end{array}$ & Maniatis et al. (1982) \\
\hline pBR322 & $a m p^{r}$ tet $^{r}$ cloning vector & Maniatis et al. (1982) \\
\hline pRS551 & lac promoter probe vector & Simons et al. 1987) \\
\hline pgln2 & $g \ln A L G^{+}$in pBR322 & Backman et al. (1981) \\
\hline pgln62 & $\mathrm{glnL}^{+}$in pBR322 & Backman et al. (1983) \\
\hline pgln31 & glnG ${ }^{+}$in $\mathrm{pBR} 322$ with no obvious promoter & Backman et al. (1983) \\
\hline pBR325 & $a^{r} p^{r}$ tet $^{r}$ chl $^{r}$ (source of chlr gene) & Maniatis et al. (1982) \\
\hline pUC4K & $a m p^{r} \operatorname{kan}^{r}$ (source of $\operatorname{kan}^{r}$ gene) & Pharmacia \\
\hline pDK4 & Bam HI of Kohara clone 149 into pUC18 & $\begin{array}{l}\text { (a reconstruction as per Allikmets } \\
\text { et al. (1993)) }\end{array}$ \\
\hline pDK5 & Pstl fragment $\left(\mathrm{kan}^{\mathrm{r}}\right)$ from pUC4K into EcoRV sites of pDK4 (Fig. 2) & \\
\hline pDK7 & BstU1 fragment (chl') from pBR325 into blunted Rsrll site of pDK4 (Fig. 2) & \\
\hline pDK9 & BstU1 fragment (chl'r ) from pBR325 into EcoRV sites of pDK4 (Fig. 2) & \\
\hline pDK10 & BamHI from pDK4 in pUC18N (Fig. 2) & \\
\hline Plasmid & Relevant genotype or construction & Source/reference \\
\hline $\begin{array}{l}\text { pDK11 } \\
\text { pglnK2 }\end{array}$ & $\begin{array}{l}\text { BstU1 fragment }\left(\mathrm{chl}^{r}\right) \text { from pBR325 into blunted Ndel site of pDK11 } \\
\text { glnK } K^{+} \text {and promoter region (PCR amplified) into pUC18. (Fig. 2) }\end{array}$ & \\
\hline pglnK3 & glnK promoter (EcoRI-BamHI) into pRS551 pWM5 $\mathrm{glnE}^{+}$in pBLUESCRIPT & W. Muse, Ph.D. thesis \\
\hline pglnE2 & Kpnl-BamHI of pWM5 (blunted) into Scal site of pBR322 & \\
\hline pglnE3 & $\begin{array}{l}\text { Nsil-Scal fragment deleted from pglnE2 and replaced with the Bst UI fragment } \\
(\mathrm{chl}) \text { from pBR325 }\end{array}$ & \\
\hline pBUC10 & $g \ln B^{+}$in pUC18 & Jiang et al. (1997) \\
\hline pBB180 & glnB-A49P in pUC18 & Jiang et al. (1997) \\
\hline
\end{tabular}

described (Maniatis et al., 1982). Transformation with linear DNA to obtain recombination onto the chromosome, was performed by electroporation of the recD strain K4633 as described (Winans et al., 1985). For this purpose, $\approx 0.5 \mu \mathrm{g}$ of the desired DNA fragment was band purified on low-meltingpoint agarose gels in $1 \times$ TAE buffer as described (Maniatis et al., 1982) and electroporated into strain K4633 using a Bio-Rad Gene Pulser apparatus. Transformants were selected on rich LB + glutamine medium supplemented with the appropriate drug. P1vir was then used to transfer the drug resistance marker and associated mutations to various strains in which the effects were assessed.

\section{Assessment of the Ntr phenotype}

The ability of cells to grow on arginine as the sole nitrogen source was examined. Previous studies had suggested that cells must be able to generate a high intracellular concentration of $\mathrm{NRI} \sim \mathrm{P}$ to use this nitrogen source (reviewed in Reitzer, 1996b).

\section{Construction of a glnK null mutation}

The DNA sequence of the 10.1 min region of the E. coli chromosome shows the presence of the $m d l$ gene, which does not have a role in nitrogen regulation, a nitrogen-regulated operon consisting of glnK and amtB (van Heeswijk et al., 1996) and tes $B$. We constructed null mutations in $m d l$, glnK and $a m t B$ by deletion of convenient restriction fragments and insertion of drug resistance markers, as depicted in Fig. 2. Our glnK null mutation is also $m d l$ and is likely to have a polar effect on amtB (Fig. 2). The null mutations were then recombined onto the E. coli chromosome (Elliott et al., 1992), moved transductionally into a fresh background and mapped relative to known markers in the $10 \mathrm{~min}$ region. The $\Delta m d l-g l n K:: c h l$, $\Delta m d l-g l n K:: k a n, m d l:: c h l$ and $a m t B:: c h l$ mutations were transductionally mapped relative to the sites of drug resistance mutations in strains CAG12017, CAG12148, CAG12154 and CAG12107 (Table 5), as well as to each other. In addition, the absence of wild-type sequences in the recombinants was confirmed by DNA typing using PCR. DNA typing of putative glnK mutants, and amplification of 
Table 6. Strain aliases.

\begin{tabular}{lll}
\hline Alias & Strain name & Reference \\
\hline G & YMC12 & Backman et al. (1981) \\
B & RB9060 & Bueno et al. (1985) \\
D & RB9040 & Bueno et al. (1985) \\
L & RB9132 & Bueno et al. (1985) \\
A & TH16 & Reitzer and Magasanik (1986) \\
P & WS6002 & Feng et al. (1992) \\
LP & WS6005 & Feng et al. (1992) \\
\hline
\end{tabular}

gInK alleles for DNA sequencing was performed as described (Saiki et al., 1990) using the following primers:

upstream, 5'-GAAGCTTGGTACCGAGGAATCATTGAGCGCCTG-3'; downstream, 5'-CGGATCCGTCGACTTCCTGTTGCTGTGTGCCAGAG-3' The DNA-typing data indicated that the $g / n K, a m t B$ and $m d l$ mutations formed in vitro and crossed onto the $E$. coli chromosome were recombined in single copy into the normal chromosomal context (data not shown).

\section{Construction of a glnK::lacZ operon fusion, and recombination of this fusion into the trp operon}

Using the known DNA sequence as a guide, PCR primers were designed to amplify the gInK control region. The glnK promoter was amplified using the following primers: (upstream primer) 5'-GGAATTCATTGAGCGCCTGAATAGCGC-3'; and (downstream primer) 5'-GGGATCCGGTAATGGTTCTGCTACACG-3'. The amplification product was cleaved with EcoRI and $B a m \mathrm{HI}$ and cloned into pRS551 (Simons et al., 1987) to form a transcriptional fusion to lac $Z$ bracketed by transcriptional termination sequences with flanking sequence homology to the trp genes. The fusion was recombined onto the $E$. coli chromosome into the trp operon by digesting the DNA with Sall, followed by electroporation into TE2680 with recombinants selected for kanamycin resistance, as described (Eliott, 1992). The recombinants were confirmed to have a new auxotrophic requirement for tryptophan, indicating correct recombination into the trp locus (Simons et al., 1987).

\section{Construction of the glnE3 allele}

The Kpnl-BamHI fragment of pWM5 (Wilson Muse, Ph.D. thesis, 1996 University of Michigan Department of Biology) was rendered blunt with T4 DNA polymerase and ligated into the Scal site of pBR322 forming pglnE2. This plasmid was cleaved with Nsil and Scal to release a fragment containing most of $g / n E$. The BstUI fragment from pBR325, containing the $c h l$ gene, was ligated into the backbone of pglnE2, forming pglnE3. The glnE3::chl allele was then recombined onto the bacterial chromosome after transformation with linear DNA, with selection for chl'. The correct chromosomal location of the mutation was confirmed by DNA typing, using the following primers: (upstream) 5'-GTGAGTGACGAAGCCGGG-3' and (downstream) 5'-GCGCCGCGGGGAATTCACTGAG-3'. The chromosomal site of insertion of the glnE3::chl allele was mapped relative to the known glnE::Tn5 allele in strain RB9017 (Bueno et al., 1985).

\section{Suppressor analysis}

Spontaneous suppressors of the growth defect of strains BDM, $\mathrm{BD} /$ pgln2 and $\mathrm{BD} /$ pgln62 on glucose-arginine medium were obtained by direct selection on glucose-arginine plates, followed by repurification on this medium.

\section{Strain nomenclature}

All strains used in this study are summarized in Table 5. To facilitate the presentation, we use a strain nomenclature in which the strain name contains a description of the relevant genotype. Thus, for example, a strain containing $\Delta g \ln L 2001$ is called $\mathrm{L}$, a strain containing $\Delta g \mathrm{ln} B$ is called $B$ and a strain containing $\Delta g \ln B \Delta g \ln L 2001 \mathrm{~g} \ln E:: c h l \Delta m d l-g \operatorname{lnK}:: k a n$ is called BLEK. In this nomenclature, the order of the letters has no significance. The names previously used for strains renamed in this work are presented in Table 6.

\section{Molecular biology techniques}

DNA manipulations were by standard methods as described (Maniatis et al., 1982). Internal primers used for DNA sequencing of $g / n K$ and $g / n K$ mutant alleles were as follows: 5'GGTCATCAGCAATCGCCAC-3', 5'-CGTCAGTAAGGCGGCTTACAC-3' and 5'-GATTATCACGGTCACCAGCTTC-3'. DNA sequencing on $3 \mu \mathrm{g}$ of plasmid DNA or $2.5 \mathrm{pmol}$ PCR amplification product was performed using a Fidelity DNA sequencing system (Oncor). Plasmid DNA for DNA sequencing was prepared using a Qiagen plasmid midi kit. PCR product was prepared for DNA sequencing using a Qiagen Qiaquick PCR purification kit.

\section{Glutamine synthetase assays}

The $\gamma$-glutamyl transferase assay was used as described previously (Atkinson and Ninfa, 1992). Results are expressed as nmol of glutamyl-hydroxamate formed $\mathrm{min}^{-1} \mathrm{mg}^{-1}$ protein. Two to six cultures were used for each determination. Total GS was determined in reactions in which $\mathrm{Mn}^{2+}$ was the sole metal ion, whereas unadenylylated GS was determined in reactions in which $\mathrm{Mg}^{2+}$ ions were present in large excess over $\mathrm{Mn}^{2+}$ ions, as described previously (reviewed in Rhee et al., 1985b). In the latter case, only unadenylylated enzyme should be active, whereas in the former case both unadenylylated and adenylylated forms of the enzyme should be equally active. However, our experience with the glnE3::chl allele suggests that, for an unknown reason, the experiments with excess $\mathrm{Mg}^{2+}$ may be under-reporting the activity of unadenylylated GS (see Results). Thus, the measurements of GS adenylylation state reported here, especially when the extent of adenylylation was low, may be systematically overestimated. Alternatively, E. coli may contain, in addition to the glnEencoded ATase, another enzyme capable of modifying GS.

\section{$\beta$-Galactosidase assays}

The assay was performed on cell sonicates using the conditions previously described (Silhavy et al., 1984). Data were calculated according to Wanner et al. (1977), and cell sonicates

(C) 1998 Blackwell Science Ltd, Molecular Microbiology, 29, 431-447 
were used as recommended by those authors except that cells were sonicated on ice in $50 \mathrm{mM}$ potassium phosphate buffer, pH7.5. Two cultures were used for each determination, and results are expressed as $\mu \mathrm{mol}$ of ONPG hydrolysed $\min ^{-1} \mathrm{mg}^{-1}$ protein.

\section{Acknowledgements}

This work was supported by grants GM47460 from the NIH and DMB9004048 from the NSF. We thank Boris Magasanik for many helpful discussions, for reviewing an earlier version of this manuscript, and for suggesting several of the experiments shown here. We thank Melina S. Williams for assistance in strain constructions. We thank Yeuling Liang for early work on the system, including the observation that the $\mathrm{Ntr}^{-}$character of strain BD could be suppressed by mutations mapping in $g \ln A L G$. We thank David Friedman and Jeff Withey for providing the K4663 strain and pRS551, for use of the electroporation apparatus, for advice on crossing mutations onto the chromosome and for reviewing an earlier version of the manuscript. We thank H. V. Westerhoff and colleagues and S. G. Kustu and colleagues for reviewing an earlier version of this manuscript. We thank Buddy Weise and Rowena S. Matthews for providing strains used for mapping, and Kelly Abshire, Robert Clark and Fred Neidhardt for providing Kohara phages and advice on their use. We thank Bob Bender and Wilson Muse for providing pWM5 and for helpful discussions.

\section{References}

Allikmets, R., Gerrard, B., Court, D., and Dean, M. (1993) Cloning and organization of the abc and mdl genes of Escherichia coli: relationship to eucaryotic multidrug resistance. Gene 136: 231-236.

Atkinson, M.R., and Ninfa, A.J. (1992) Characterization of mutations in the glnL gene of Escherichia coli affecting nitrogen regulation. J Bacteriol 174: 4538-4548.

Atkinson, M.R., Kamberov, E.S., Weiss, R.L., and Ninfa, A.J. (1994) Reversible uridylylation of the Escherichia coli PII signal transduction protein regulates its ability to stimulate the dephosphorylation of the transcription factor Nitrogen Regulator I (NRI or NtrC). J Biol Chem 269: 2828828293.

Atkinson, M.R., and Ninfa, A.J. (1993) Mutational analysis of the bacterial protein kinase/phosphatase NRII. J Bacteriol 175: 7016-7023.

Backman, K., Chen, Y.-M., and Magasanik, B. (1981) Physi$\mathrm{cal}$ and genetic characterization of the $g \ln A-g \ln G$ region of the Escherichia coli chromosome. Proc Natl Acad Sci USA 78: 3743-3747.

Backman, K., Chen, Y.-M., Ueno-Nishio, S., and Magasanik, B. (1983) The product of glnL is not essential for the regulation of bacterial nitrogen assimilation. J Bacteriol 154: 516-519.

Bancroft, S., Rhee, S.G., Neumann, C., and Kustu, S. (1978) Mutations that alter the covalent modification of glutamine synthetase in Salmonella typhimurium. J Bacteriol 134: 1046-1055.

Bueno, R., Pahel, G., and Magasanik, B. (1985) Role of $g \ln B$ and $g \ln D$ gene products in the regulation of the $g \ln A L G$ operon of Escherichia coli. J Bacteriol 164: 816-822.

Carr, P.D., Cheah, E., Suffolk, P.M., Vasudevan, S.G., Dixon, N.E., and Ollis, D.L. (1996) X-ray structure of the signal transduction protein PII from Escherichia coli at $1.9 \mathrm{~A}$. Acta Cryst D52: 93-104.

Deretic, V., Leveau, J.H.J., Mohr, C.D., and Hilber, N.S. (1992) In vitro phosphorylation of AlgR, a regulator of mucoidy in Pseudomonas aeruginosa, by a histidine protein kinase and effects of small phospho-donor molecules. Mol Microbiol 6: 2761-2767.

de Zamaroczy, M.A., Paquelin, A., Peltre, G., Forchhammer, K., and Elmerich, C. (1996) Coexistence of two structurally similar but functionally different PII proteins in Azospirillum brasilense. J Bacteriol 178: 4143-4149.

Elliott, T. (1992) A method for constructing single-copy lac fusions in Salmonella typhimurium and its application to the hemA-prfA operon. J Bacteriol 174: 245-253.

Feng, J., Atkinson, M.R., McCleary, W., Stock, J.B., Wanner, B.L., and Ninfa, A.J. (1992) Role of phosphorylated metabolic intermediates in the regulation of glutamine synthetase synthesis in Escherichia coli. J Bacteriol 174: 6061-6070.

Feng, J., Goss, T.J., Bender, R.A., and Ninfa, A.J. (1995) Activation of the nac promoter of Klebsiella aerogenes. $J$ Bacteriol 177: 5523-5534.

Flashner, Y., Weiss, D.S., Keener, J., and Kustu, S. (1995) Constitutive forms of the enhancer-binding protein NtrC: evidence that essential oligomerization determinants lie in the central activation domain. $J$ Mol Biol 249: 700713.

Hoch, J.A., and Silhavy, T. J. (eds). (1995) Two Component Signal Transduction. Washington, DC: ASM.

Jiang, P., Zucker, P., Atkinson, M.R., Kamberov, E.S., Tirasophon, W., Chandran, P., et al. (1997) Structure/function analysis of the PII signal transduction protein of Escherichia coli. Genetic separation of the interactions with receptors. J Bacteriol 179: 4342-4353.

Jiang, P., Peliska, J.A., and Ninfa, A.J. (1998) Enzymological characterization of the signal-transducing uridylyltransferase/uridylyl-removing enzyme of Escherichia coli and its interaction with the PII protein. (submitted).

Kamberov, E.S., Atkinson, M.R., Ninfa, E.G., Feng, J., and Ninfa, A.J. (1994) Regulation of Bacterial Nitrogen Assimilation by the Two-Component System NRI and NRII (NtrC and NtrB). In Cellular and Molecular Biology of Phosphate and Phosphorylated Compounds in Microorganisms. Torriani-Gorini, A., Yagil, E., and Silver, S. (eds). Washington DC: American Society for Microbiology, pp. 302-308.

Kamberov, E.S., Atkinson, M.R., and Ninfa, A.J. (1995) The Escherichia coli PII signal transduction protein is activated upon binding 2-ketoglutarate and ATP. J Biol Chem 270: 17797-17807.

Lukat, G.S., McCleary, W.R., Stock, A.M., and Stock, J.B. (1992) Phosphorylation of bacterial response regulator proteins by low molecular weight phospho-donors. Proc Natl Acad Sci USA 89: 718-722.

McCleary, W.R. (1996) The activation of PhoB by acetylphosphate. Mol Microbiol 20: 1155-1163.

McCleary, W.R., and Stock, J.B. (1994) Acetyl phosphate 
and the activation of two-component response regulators. J Biol Chem 269: 31567-31572.

McCleary, W.R., Stock, J.B., and Ninfa, A.J. (1993) Is acetyl phosphate a global signal in Escherichia coli? J Bacteriol 175: 2793-2798.

MacNeil, T., MacNeil, D., and Tyler, B. (1982a) Fine-structure deletion map and complementation analysis of the $g \ln A$ glnG region in Escherichia coli. J Bacteriol 150: 13021313.

MacNeil, T., Roberts, G.P., MacNeil, D., and Tyler, B. (1982b) The products of $g / n L$ and $g \ln G$ are bifunctional regulatory proteins. Mol Gen Genet 188: 325-333.

Magasanik, B. (1996) Regulation of nitrogen utilization. In Escherichia coli and Salmonella. Cellular and Molecular Biology, 2nd edn. Neidhardt, F.C. (editor in chief). Washington. DC: American Society for Microbiology Press, pp. 1344-1356.

Maniatis, T., Fritsch, E.F., and Sambrook, J. (1982) In Molecular Cloning, A Laboratory Manual. Cold Spring Harbor Laboratory, Cold Spring Harbor, New York. p. 68 and p. 250.

Merrick, M., and Edwards, R.A. (1995) Nitrogen Control in Bacteria. Microbiol Rev 59: 604-622.

Miller, J.H. (1992) A Short Course in Bacterial Genetics. A Laboratory Manual and Handbook for Escherichia coli and Related Bacteria. Cold Spring Harbor NY: Cold Spring Harbor Press, pp. 6.10-6.11.

Ninfa, A.J. (1996) Regulation of gene transcription by extracellular stimuli. In Escherichia coli and Salmonella. Cellular and Molecular Biology, 2nd edn. Neidhardt, F.C. (editor in chief). Washington DC: American Society for Microbiology Press, pp. 1246-1261.

Ninfa, A.J., and Magasanik, B. (1986) Covalent modification of the glnG product, NRI, by the gInL product, NRII, regulates the transcription of the gInALG operon in Escherichia coli. Proc Natl Acad Sci USA 83: 5909-5913.

Ninfa, A.J., Atkinson, M.R., Kamberov, E.S., Feng, J., and Ninfa, E.G. (1995) Control of Bacterial Nitrogen Assimilation by the NRI-NRII Two Component System of Enteric Bacteria. In Two Component Systems of Bacteria. Silhavy, T.J. and Hoch, J.A. (eds). Washington, DC: American Society for Microbiology, pp. 67-88.

Pahel, G., Rothstein, D.M., and Magasanik, B. (1982) Complex glnA-glnL-glnG operon of Escherichia coli. J Bacteriol 150: 202-213.

Parkinson, J.S., and Kofoid, E.C. (1992) Communication modules in bacterial signalling proteins. Annu Rev Genet 26: 71-112.

Pruss, B.M., and Wolfe, A.J. (1994) Regulation of acetyl phosphate synthesis and degradation, and the control of flagellar expression in Escherichia coli. Mol Microbiol 12: 973-984.

Reitzer, L.J. (1996a) Ammonia assimilation and the biosynthesis of glutamine, glutamate, aspartate, asparagine, L-alanine, and D-alanine. In Escherichia coli and Salmonella. Cellular and Molecular Biology, 2nd edn. Neidhardt, F.C. (editor in chief). Washington DC: American Society for Microbiology Press, pp. 391-407.

Reitzer, L.J. (1996b) Sources of Nitrogen and their utilization. In Escherichia coli and Salmonella. Cellular and Molecular Biology, 2nd edn. Neidhardt, F.C. (editor in chief). Washington. DC: American Society for Microbiology Press, pp. 380-390.

Reitzer, L.J., and Magasanik, B. (1986) Transcription of $g \ln A$ in $E$. coli is stimulated by activator bound to sites far from the promoter. Cell 45: 785-792.

Rhee, S.G., Park, S.C., and Koo, J.H. (1985a) The role of adelylyltransferase and uridylyltransferase in the regulation of glutamine synthetase in Escherichia coli. In Current topics in Cellular Regulation, Vol. 27. Shalteil, S. and Chock, P.B. (eds). New York: Academic Press, pp. 221-232.

Rhee, S.G., Chock, P.B., and Stadtman, E.R. (1985b) Glutamine synthetase from Escherichia coli. Methods Enzymol 113: 213-241.

Rhee, S.G., Chock, P.B., and Stadtman, E.R. (1989) Regulation of Escherichia coli glutamine synthetase. Adv Enzymol (Rel areas Mol Biol) 62: 37-92.

Saiki, R.K. (1990) Amplification of genomic DNA. In PCR Protocols, a Guide to Methods and Applications. Innis, M.A., Gelfand, D.H., Sninsky, J.J., and White, T.J. (eds). San Diego, Academic Press, pp. 13-20.

Shiau, S.-P., Schneider, B.L., Gu, W., and Reitzer, L.J. (1992) Role of nitrogen regulator I (NtrC), the transcriptional activator of $g \ln A$ in enteric bacteria, in reducing expression of $g \ln A$ during nitrogen-limiting growth. $J$ Bacteriol 174: 179-185.

Silhavy, T.J., Berman, M.L., and Enquist, L.W. (1984) Experiments with Gene Fusions. Cold Spring Harbor, NY: Cold Spring Harbor Laboratory Press.

Simons, R.W., Houman, F., and Kleckner, N. (1987) Improved single copy and multicopy lac-based cloning vectors for protein and operon fusions. Gene 53: 85-96.

Stadtman, E.R., Ciardi, J.E., Yeh, J., Henning, S.B., and Shapiro, B.M. (1970) Multiple molecular forms of glutamine synthetase produced by enzyme catalyzed adenylylation and deadenylylation reactions. Adv Enzyme Regul 8: 99118.

Ueno-Nishio, S., Mango, S., Reitzer, L.J., and Magasanik, B. (1984) Identification and regulation of the glnL operatorpromoter of the complex $g \operatorname{InALG}$ operon of Escherichia coli. J Bacteriol 160: 379-384.

van Heeswijk, W.C., Rabenberg, M., Westerhoff, H.V., and Kahn, D. (1993) The genes of the glutamine synthetase adenylylation cascade are not regulated by nitrogen in Escherichia coli. Mol Microbiol 9: 443-457.

van Heeswijk, W.C., Syegman, B., Hoving, S., Molenaar, D., Kahn, D., and Westerhoff, H.V. (1995) An additional PII in Escherichia coli: a new regulatory protein in the glutamine synthetase cascade. FEMS Microbiol Lett 132: 153-157.

van Heeswijk, W.C., Hoving, S., Molenaar, D., Stegman, B., Kahn, D., and Westerhoff, H.V. (1996) An alternative PII protein in the regulation of glutamine synthetase in Escherichia coli. Mol Microbiol 21: 133-146.

Wanner, B.L., Kodaira, R., and Neidhardt, F.C. (1977) Physiological regulation of a decontrolled lac operon. J Bacteriol 130: 212-222.

Wanner, B.L., and Wilmes-Reisenberg, M.R. (1992) Involvement of phosphotransacetylase, acetate kinase, and acetyl phosphate synthesis in control of the phosphate regulon in Escherichia coli. J Bacteriol 174: 21242130. 
Weglensky, P., Ninfa, A.J., Ueno-Nishio, S., and Magasanik, B. (1989) Mutations in the glnG gene of Escherichia coli resulting in increased activity of nitrogen regulator I. J Bacteriol 171: 4479-4485.
Winans, S.C., Elledge, S.J., Krueger, J.H., and Walker, G.C. (1985) Site-directed insertion and deletion mutagenesis with cloned fragments in Escherichia coli. J Bacteriol 161: 1219-1221. 